\title{
\begin{tabular}{l|l} 
Mibraries & DSpace@MIT
\end{tabular}
}

\author{
MIT Open Access Articles
}

\section{Information Shocks, Liquidity Shocks, Jumps, and Price Discovery: Evidence from the U.S. Treasury Market}

The MIT Faculty has made this article openly available. Please share how this access benefits you. Your story matters.

Citation: Jiang, George J., Ingrid Lo, and Adrien Verdelhan. “Information Shocks, Liquidity Shocks, Jumps, and Price Discovery: Evidence from the U.S. Treasury Market.” Journal of Financial and Quantitative Analysis 46.02 (2010): 527-551. Web. (C) Cambridge University Press 2010.

As Published: http://dx.doi.org/10.1017/S0022109010000785

Publisher: Cambridge University Press

Persistent URL: http://hdl.handle.net/1721.1/72081

Version: Final published version: final published article, as it appeared in a journal, conference proceedings, or other formally published context

Terms of Use: Article is made available in accordance with the publisher's policy and may be subject to US copyright law. Please refer to the publisher's site for terms of use. 


\title{
Information Shocks, Liquidity Shocks, Jumps, and Price Discovery: Evidence from the U.S. Treasury Market
}

\author{
George J. Jiang, Ingrid Lo, and Adrien Verdelhan*
}

\begin{abstract}
In this paper, we identify jumps in U.S. Treasury-bond (T-bond) prices and investigate what causes such unexpected large price changes. In particular, we examine the relative importance of macroeconomic news announcements versus variation in market liquidity in explaining the observed jumps in the U.S. Treasury market. We show that while jumps occur mostly at prescheduled macroeconomic announcement times, announcement surprises have limited power in explaining bond price jumps. Our analysis further shows that preannouncement liquidity shocks, such as changes in the bid-ask spread and market depth, have significant predictive power for jumps. The predictive power is significant even after controlling for information shocks. Finally, we present evidence that post-jump order flow is less informative relative to the case where there is no jump at announcement.
\end{abstract}

\section{Introduction}

In this paper, we examine unexpected large and discontinuous changes, known as jumps, in U.S. Treasury-bond (T-bond) prices. In contrast to continuous price changes, jumps are known to have distinctly different implications for risk measurement and management, portfolio allocation, as well as valuation of derivative securities. It is thus important to understand the magnitude of jump risk in the U.S. Treasury market. Moreover, it is important to understand what causes these large price changes and how the market behaves prior to and after the jumps.

*Jiang, gjiang@email.arizona.edu, Eller College of Management, University of Arizona, PO Box 210108, Tucson, AZ 85721; Lo, ingridlo@bankofcanada.ca, Financial Markets Department, Bank of Canada, 234 Wellington St., Ottawa, ONT K1A 0G9, Canada; and Verdelhan, adrienv@mit.edu, Sloan School of Management, Massachusetts Institute of Technology, 77 Massachusetts Ave., \#E62621, Cambridge, MA 02139. We are particularly grateful for the guidance and comments provided by Hendrik Bessembinder (the editor) and Christopher Neely (the referee). We also thank Torben Andersen, Greg Bauer, Bruno Biais, Tim Bollerslev, Michael Fleming, Thierry Foucault, Scott Hendry, Jordan Neyland, Roel Oomen, Dagfinn Rime, Kenneth Roskelley, Kelvin Shepherd, Georghio Theocharides, Rossen Valkanov, and seminar participants at the Bank of Canada, the 2007 Singapore International Conference of Finance, the 3rd Annual Central Bank Workshop on the Microstructure of Financial Markets, 2008 Stanford Institute for Theoretical Economics summer workshop, the 2nd Annual Risk Management Conference in Singapore, and 2008 China International Conference in Finance for their helpful comments and suggestions. The usual disclaimer applies. 
The focus of the paper is to examine the extent to which jumps are explained by macroeconomic news announcements, ${ }^{1}$ and in particular the relative importance of macroeconomic news announcements versus variation in market liquidity in explaining the observed jumps. In addition, recent studies (e.g., Brandt and Kavajecz (2004)) show that order flow imbalances are informative and play an important role in T-bond price discovery. In our study, to understand how jumps affect price discovery we further examine the informativeness of order flow immediately after bond price jumps.

The jump test used in our study is the "variance swap" approach proposed in Jiang and Oomen (2008). This method is based on an intuition long established in the finance literature: In the absence of jumps, the difference between simple return and $\log$ return captures $1 / 2$ of the instantaneous return variance. As such, variance swap can be perfectly replicated using the log contract (see Neuberger (1994)). However, in the presence of jumps the replication strategy is imperfect, and the replication error, as a function of realized jumps, can be used to identify jumps. The data used in our study are from BrokerTec, an interdealer electronic trading platform, and contain around-the-clock trades and quotes for on-the-run 2-, 3-, 5-, and 10-year notes and 30-year bonds. ${ }^{2}$ Based on 5-minute data from January 2004 to June 2007, we identify a large number of jumps for all maturities. For example, there are 120 jumps in the 2-year note prices during our sample period. Overall, the average jump size is more than 10 times the 5-minute return standard deviation.

With identified jumps, we search for potentially related economic news or events. The approach is similar to that of Fleming and Remolona (1997) and Bollerslev, Cai, and Song (2000). ${ }^{3}$ We identify an extensive list of prescheduled macroeconomic news and events as potential causes of bond price jumps. The list includes major news announcements widely considered in the existing literature, such as initial jobless claims, consumer price index, change in nonfarm

\footnotetext{
${ }^{1}$ In this aspect, our study is different from the existing literature that examines the effect of macroeconomic announcements on bond prices. For instance, Fleming and Remolona (1999) examine a 2stage adjustment process for prices, trading volume, and bid-ask spreads in the U.S. Treasury market in response to the arrival of public news announcements. Balduzzi, Elton, and Green (2001) use intraday data to investigate the effects of scheduled macroeconomic announcements on bond prices, trading volume, and bid-ask spreads. Green (2004) further studies the impact of trading on government bond prices and finds a significant increase in the informational role of trading following economic announcements. Pasquariello and Vega (2007) analyze the role of private and public information in the U.S. T-bond price discovery process by studying the response of bond yields to order flow and U.S. macroeconomic news. Extending the above studies, Menkveld, Sarkar, and van der Wel (2010) examine the effect of macroeconomic announcements on the 30-year U.S. T-bond futures market activities. Brandt, Kavajecz, and Underwood (2007) examine price discovery in the futures market and the interaction with the cash market.

${ }^{2}$ Based on 2005 data, the BrokerTec electronic trading platform accounts for about $60 \%$ of trading activity for these securities. In addition, trading volume on BrokerTec is comparable to that of the U.S. equity market. In 2006, trading volume of on-the-run 2-, 3-, 5-, and 10-year notes and 30-year bonds on BrokerTec reached $\$ 103.4$ billion, whereas trading volume of the U.S. equity market is about $\$ 110$ billion.

${ }^{3}$ Fleming and Remolona (1997) examine the 25 largest price changes of the on-the-run U.S. 5-year notes from August 1993 to August 1994 and find that they are all associated with news announcements. Bollerslev et al. (2000) find that the 25 largest absolute 5-minute returns in the Treasury futures market over 1994-1997 are associated with news announcements.
} 
payrolls, retail sales, producer price index, consumer confidence, and the Institute for Supply Management (ISM) index. It also includes announcements that have been considered less important and thus largely omitted in previous studies, for example, the NY Empire State Index (a regional economic indicator published by the Federal Reserve Bank of New York). Overall, we find that a large number of jumps occur during prescheduled macroeconomic news announcements. For example, about $90 \%$ of jumps in the 2-year note prices occur within 10 minutes of prescheduled news announcement times.

While a majority of jumps occurs at prescheduled news announcement times, further analysis shows that information shocks, constructed from news announcement surprises, have limited power in explaining jumps in bond prices. We find that preannouncement liquidity shocks also play an important role in bond price jumps. In our analysis, we use several measures constructed from the BrokerTec data to capture liquidity shocks. They include the bid-ask spread, trading volume, and various measures of market depth. Similar to Fleming and Remolona (1999), we document stylized preannouncement effects in the U.S. Treasury market. In particular, there is generally a widening of the bid-ask spread and a sharp drop in market depth prior to a news announcement. More importantly, we find that the widening of the spread and the drop in market depth during the preannouncement period are more significant on days with jumps than on those without jumps. As discussed in Fleming and Piazzesi (2006), dealers tend to withdraw orders and place orders further out to avoid being picked off in the upcoming information event. Such activities lead to the widening of the bid-ask spread and decreasing of market depth, which, in turn, could potentially lead to large price changes at news announcement.

To examine the explanatory power of information shocks versus liquidity shocks for jumps in bond prices, we specify and estimate a probit model to examine the interaction between liquidity shocks and announcement surprises. The results show that, first, preannouncement liquidity shocks, in particular shocks to the bid-ask spread and market depth, have significant predictive power regarding jump frequency in bond prices. Second, consistent with existing studies by Fleming and Remolona (1999), Balduzzi et al. (2001), and Green (2004), there is a significantly positive relation between announcement surprises and jumps. Third and most interesting, liquidity shocks remain significant in predicting jumps even after we control for the effect of announcement surprises. In other words, the predictive power of liquidity shocks for upcoming jumps is not subsumed by information contained in announcement surprises. The findings suggest that liquidity shocks contribute to jumps beyond the effect of unexpected information shocks.

Finally, we examine the post-jump price discovery process of the U.S. Treasury market. Recent studies have examined the information content of order flow around announcements. Green (2004) finds that postannouncement order flow has higher information content in the 5-year T-note relative to nonannouncement days. Menkveld et al. (2010) provide similar findings for the 30-year T-bond futures. Brandt and Kavajecz (2004) find that order flow imbalances account for up to $26 \%$ of the day-to-day variation in yields on days without major macroeconomic announcements. We extend the existing literature and examine how jumps affect the bond price discovery process. Our results show that order flow has 
significantly less effect on bond prices after jumps occur at announcement times. We note that the lesser informational role of order flow after a jump is not due to a lack of trading. In fact, we observe a surge of trading volume during the post-jump period. We provide a plausible explanation of the findings based on the dispersion of investor belief. Pasquariello and Vega (2007) show that the information content of order flow is positively related to the dispersion of investor belief. The patterns documented in our study suggest that when information uncertainty at announcement is resolved in a dramatic form of jumps, the dispersion of investor belief is reduced, and thus, order flow becomes less informative.

The rest of the paper proceeds as follows. Section II describes the data and the jump test. Section III presents summary statistics of identified jumps and market activities around jumps. Section IV examines the explanatory power of macroeconomic announcements versus liquidity shocks for jumps. In addition, we also examine the effect of jumps on the bond price discovery process. Section $\mathrm{V}$ concludes.

\section{Data and Methodology}

\section{A. Data}

The U.S. Treasury securities data are obtained from BrokerTec, an interdealer electronic trading platform in the secondary wholesale U.S. Treasury securities market. Prior to 1999, the majority of interdealer trading of U.S. Treasuries occurred through interdealer brokers. After 1999, 2 electronic trading platforms emerged: eSpeed and BrokerTec. Since then, the trading of on-the-run Treasuries has migrated to the electronic platforms. Mizrach and Neely (2009) and Fleming and Mizrach (2009) provide detailed descriptions of the migration to electronic platforms and price discovery on the BrokerTec platform. According to Barclay, Hendershott, and Kotz (2006), the electronic market shares for the 2-, 5-, and 10 -year bonds are, respectively, $75.2 \%, 83.5 \%$, and $84.5 \%$ during the period from January 2001 to November 2002. By the end of 2004, the majority of secondary interdealer trading was through electronic platforms, with over $95 \%$ of the trading of active issues on electronic platforms. ${ }^{4}$

BrokerTec is more active in the trading of 2-, 3-, 5-, and 10-year T-notes than eSpeed. Our data also include the 30-year bond, although eSpeed has more active trading for this maturity. The sample period is from January 2004 to June 2007. Days with early closing before public holidays are excluded, as liquidity is typically low for these days. The data set consists of over 700.8 million observations and 16.9 million transactions. Over our sample period, there is strong growth in trading volume on the BrokerTec platform. The average daily trading volume of all maturities goes up from $\$ 53.0$ billion in $2004, \$ 80.2$ billion in 2005 , and $\$ 103.4$ billion in 2006 to $\$ 115.5$ billion in the first half of 2007 . The BrokerTec platform functions as a limit order book. Traders can submit limit orders, that is, orders that specify both price and quantity posted on the book, or

\footnotetext{
${ }^{4}$ See "Speech to the Bond Market Association," December 8, 2004, by Michael Spencer, founder and chief executive of ICAP PLC.
} 
they can submit marketable limit orders, that is, orders with a price better than or equal to the best price on the opposite side of the market, to ensure immediate execution. Limit order submitters can post "iceberg" orders, where only part of their order is visible to the market and the remaining part is hidden. All orders on the book except the hidden parts of the orders are observed by market participants. The orders remain in the market until matched, deleted, inactivated, loss of connectivity, or market close. The market operates more than 22 hours a day from Monday to Friday. After the market closes at 5:30 PM Eastern Time (ET), it opens again at 7:00 PM ET. The data set contains the tick-by-tick observations of transactions, order submissions, and order cancellations. It includes the time stamp of transactions, quotes, the quantity entered and deleted, the side of the market, and, in the case of a transaction, an aggressor indicator. Fleming and Mizrach (2009) provide a more detailed description of the microstructure of the BrokerTec platform.

We use data from 7:30 AM ET to 5:00 PM ET, since trading is more active during this time interval. This interval also contains all prescheduled U.S. news announcements, and it provides 9.5 hours of trading and 114 five-minute return observations each day. While tick-by-tick data are available in our data set, we are cautious about using ultra-high-frequency data because of the concerns of market microstructure effects. Due to discrete tick size, market microstructure noise tends to aggravate as sampling frequency increases. In addition, the choice of working with 5-minute returns is also consistent with many existing studies, such as Fleming and Remolona (1999), Balduzzi et al. (2001), and others.

Table 1 provides descriptive statistics of the data. Spreads are defined both in relative terms and in ticks. Relative spread is defined as \\ RELATIVE_SPREAD = (BEST_BID_PRICE - BEST_ASK_PRICE)/ MID-QUOTE,}

measured at the end of each 5-minute interval and averaged over the trading day. Tick spread is also measured at the end of each 5-minute interval and averaged over the trading day. As mentioned in Fleming and Mizrach (2009), the tick size of the 2-, 3-, and 5-year notes is 1/128, whereas that of the 10-year note and 30 -year bond is $1 / 64$. Daily return volatility is calculated as the square root of the sum of squared log mid-quote difference sampled at 5-minute intervals:

$$
\text { RETURN_VOLATILITY }=\left(\sum_{i=1}^{114}\left(\ln p_{i}-\ln p_{i-1}\right)^{2}\right)^{1 / 2},
$$

where the mid-quote is defined as $p_{i}=$ (BEST_BID_PRICE + BEST_ASK_ PRICE)/2. The average (hidden) depth (in millions) at the best bid/ask is the total (hidden) observed depth at the best price on both the bid and ask sides of the market measured at the end of each 5-minute interval and averaged over the trading day. The average depth and average hidden depth in the entire order book are defined similarly.

BrokerTec is a highly liquid platform over our sample period. As indicated in Panels A, D, and C of Table 1, the relative spread is smallest for the 2-year 
TABLE 1

Summary Statistics of Market Activities

Table 1 reports the summary statistics of daily trading volume (\$billions), daily return volatility (\%) of 5-minute returns based on the mid bid-ask quote from 7:00 AM to 5:00 PM, trade duration (seconds), relative spread $(\times 10,000)$ and spread in ticks average depth at the best bid and ask (\$millions), average depth in the entire order book (\$millions), average hidden depth at the best bid and ask (\$millions), and average hidden depth in the entire book during the sample period from January 5 , 2004 to June 29, 2007. Spread and depth variables are averaged over 5-minute intervals of the trading day.

\begin{tabular}{|c|c|c|c|c|c|c|c|}
\hline Variable & Mean & Median & Std. Dev. & Max. & Min. & Skewness & Kurtosis \\
\hline \multicolumn{8}{|l|}{ Panel A. 2-Year Note } \\
\hline Spread (in ticks) & 0.86 & 0.84 & 0.07 & 1.55 & 0.78 & 3.80 & 25.81 \\
\hline Relative spread $(\times 10,000)$ & 1.09 & 1.06 & 0.09 & 1.98 & 0.99 & 3.91 & 27.28 \\
\hline Trading volume (\$billions) & 25.86 & 23.94 & 12.18 & 108.83 & 6.05 & 1.61 & 8.07 \\
\hline Trade duration (seconds) & 13.69 & 13.17 & 8.36 & 48.21 & 0.09 & 0.32 & 3.21 \\
\hline Return volatility (\%) & 0.07 & 0.06 & 0.04 & 0.57 & 0.03 & 5.04 & 45.65 \\
\hline Depth at the best bid and ask (\$mil) & 547.09 & 509.98 & 334.78 & $1,567.41$ & 63.27 & 0.35 & 1.98 \\
\hline Hidden depth at the best bid and ask (\$mil) & 28.02 & 22.37 & 22.46 & 285.27 & 1.82 & 3.39 & 28.14 \\
\hline Depth of the entire order book (\$mil) & $4,092.43$ & $3,348.95$ & $3,136.67$ & $11,980.99$ & 145.32 & 0.40 & 1.90 \\
\hline Hidden depth of the entire order book (\$mil) & 70.81 & 54.72 & 61.36 & 561.15 & 3.89 & 2.72 & 14.87 \\
\hline \multicolumn{8}{|l|}{ Panel B. 3-Year Note } \\
\hline Spread (in ticks) & 1.08 & 0.95 & 0.33 & 3.23 & 0.82 & 3.09 & 14.90 \\
\hline Relative spread $(\times 10,000)$ & 1.37 & 1.21 & 0.42 & 4.13 & 1.04 & 3.11 & 14.88 \\
\hline Trading volume (\$billions) & 8.69 & 7.94 & 4.51 & 32.29 & 1.70 & 1.24 & 5.66 \\
\hline Trade duration (seconds) & 23.50 & 19.40 & 18.21 & 104.33 & 0.11 & 1.19 & 4.64 \\
\hline Return volatility (\%) & 0.11 & 0.10 & 0.07 & 0.76 & 0.04 & 4.34 & 31.32 \\
\hline Depth at the best bid and ask (\$mil) & 148.19 & 139.59 & 101.39 & 437.32 & 15.57 & 0.44 & 1.98 \\
\hline Hidden depth at the best bid and ask (\$mil) & 7.81 & 5.80 & 8.15 & 111.75 & 0.00 & 5.62 & 60.54 \\
\hline Depth of the entire order book (\$mil) & 992.04 & 753.69 & 827.43 & $3,386.37$ & 42.18 & 0.65 & 2.31 \\
\hline Hidden depth of the entire order book (\$mil) & 20.27 & 12.60 & 23.46 & 258.70 & 0.00 & 3.81 & 26.01 \\
\hline \multicolumn{8}{|l|}{ Panel C. 5-Year Note } \\
\hline Spread (in ticks) & 0.99 & 0.94 & 0.18 & 2.40 & 0.81 & 3.48 & 20.62 \\
\hline Relative spread $(\times 10,000)$ & 1.26 & 1.18 & 0.22 & 3.02 & 1.03 & 3.45 & 20.20 \\
\hline Trading volume (\$billions) & 23.43 & 22.05 & 9.50 & 67.81 & 5.65 & 0.99 & 4.63 \\
\hline Trade duration (seconds) & 5.78 & 5.28 & 3.71 & 23.94 & 0.06 & 0.70 & 4.34 \\
\hline Return volatility (\%) & 0.18 & 0.16 & 0.10 & 1.66 & 0.06 & 5.98 & 67.36 \\
\hline Depth at the best bid and ask (\$mil) & 107.13 & 107.50 & 51.64 & 237.99 & 20.90 & 0.32 & 2.09 \\
\hline Hidden depth at the best bid and ask (\$mil) & 6.24 & 5.09 & 4.40 & 39.37 & 0.14 & 1.85 & 9.20 \\
\hline Depth of the entire order book (\$mil) & $1,142.62$ & 939.02 & 861.82 & $3,819.46$ & 81.98 & 0.84 & 2.91 \\
\hline Hidden depth of the entire order book (\$mil) & 33.54 & 23.35 & 102.25 & $2,883.53$ & 1.22 & 26.03 & 723.85 \\
\hline \multicolumn{8}{|l|}{ Panel D. 10-Year Note } \\
\hline Spread (in ticks) & 1.87 & 1.80 & 0.24 & 3.35 & 1.60 & 2.69 & 12.21 \\
\hline Relative spread $(\times 10,000)$ & 1.18 & 1.13 & 0.15 & 2.14 & 0.99 & 2.72 & 12.51 \\
\hline Trading volume (\$billions) & 20.70 & 19.82 & 8.94 & 69.64 & 4.14 & 0.85 & 4.67 \\
\hline Trade duration (seconds) & 5.65 & 4.95 & 3.85 & 22.49 & 0.06 & 0.80 & 3.96 \\
\hline Return volatility (\%) & 0.30 & 0.28 & 0.15 & 1.92 & 0.11 & 4.48 & 37.74 \\
\hline Depth at the best bid and ask (\$mil) & 108.71 & 108.39 & 49.54 & 243.36 & 16.46 & 0.23 & 2.29 \\
\hline Hidden depth at the best bid and ask (\$mil) & 5.16 & 4.32 & 3.75 & 30.31 & 0.13 & 2.24 & 11.75 \\
\hline Depth of the entire order book (\$mil) & $1,347.02$ & $1,117.87$ & 910.89 & $3,739.46$ & 81.28 & 0.55 & 2.18 \\
\hline Hidden depth of the entire order book (\$mil) & 31.53 & 25.90 & 26.08 & 257.22 & 1.29 & 3.21 & 21.84 \\
\hline \multicolumn{8}{|l|}{ Panel E. 30-Year Bond } \\
\hline Spread (in ticks) & 4.00 & 3.16 & 2.47 & 28.79 & 2.20 & 3.99 & 25.53 \\
\hline Relative spread $(\times 10,000)$ & 2.65 & 2.13 & 1.68 & 19.09 & 1.38 & 3.88 & 24.12 \\
\hline Trading volume (\$billions) & 2.47 & 2.21 & 1.52 & 10.94 & 0.13 & 1.12 & 5.38 \\
\hline Trade duration (seconds) & 45.30 & 24.77 & 64.94 & 612.96 & 0.14 & 3.66 & 20.48 \\
\hline Return volatility (\%) & 0.54 & 0.49 & 0.25 & 4.26 & 0.22 & 5.69 & 70.60 \\
\hline Depth at the best bid and ask (\$mil) & 12.06 & 11.43 & 3.80 & 23.79 & 3.17 & 0.58 & 3.24 \\
\hline Hidden depth at the best bid and ask (\$mil) & 1.09 & 0.87 & 1.01 & 11.31 & 0.00 & 3.68 & 28.25 \\
\hline Depth of the entire order book (\$mil) & 117.44 & 110.85 & 71.61 & 350.57 & 3.87 & 0.57 & 3.02 \\
\hline Hidden depth of the entire order book (\$mil) & 5.51 & 3.55 & 6.42 & 54.34 & 0.01 & 3.40 & 19.80 \\
\hline
\end{tabular}

note with a sample mean of $0.0109 \%$, followed by the 10 -year note $(0.0118 \%)$ and 5-year note $(0.0126 \%)$. Trading volume is highest for the 2-year note $(\$ 25.86$ billion per day), followed by the 5-year note ( $\$ 23.43$ billion per day), and 10-year note ( $\$ 20.70$ billion per day). In terms of trading duration, the 10 -year note is most frequently traded, with an average duration of 5.65 seconds. This is closely 
followed by the 5-year note at 5.78 seconds. The average trading duration of the 2 -year note is 13.69 seconds. The result suggests that the average trade size is larger for the 2-year note than the 5- and 10-year notes. Intraday return volatility generally increases with maturity, possibly due to higher bid-ask spread and less market depth at longer maturities. The 2-year note has the deepest book, both at the best quote (\$547.09 million) and the entire book ( $\$ 4,092.43$ million). Hidden depth is low in general, and hidden order at the best quote is less than $5 \%$ of the observed depth at the best quote for all 5 maturities.

Data on macroeconomic news announcements and the survey of market participants come from Bloomberg and Briefing.com's economic calendar. Balduzzi et al. (2001) show that professional forecasts based on surveys are neither biased nor stale. To ensure the list of announcements is comprehensive, we start with the 25 announcements from Pasquariello and Vega (2007). We then check whether the timing of each jump coincides with any other announcements using information from Briefing.com's economic calendar, which features a comprehensive list of prescheduled announcements. This way, we include 7 additional economic announcements: Federal Open Market Committee (FOMC) minutes, ISM service, NY Empire State Index, Chicago Purchasing Managers Index (PMI), existing home sales, Philadelphia Fed Index, and the ADP National Employment Report sponsored by Automatic Data Processing, Inc. In addition to prescheduled news announcements, we also collect the release times of auction results for 2-, 3-, 5-, and 10-year notes. Last, we collect the release of the testimony of the Semiannual Monetary Policy Report and Economic Outlook. The full list of announcements can be found in Table 2. Following Balduzzi et al. and Andersen, Bollerslev, Diebold, and Vega (2007), the standardized announcement surprise is defined as

$$
\mathrm{SUR}_{k, t}=\frac{\mathrm{A}_{k, t}-\mathrm{E}_{k, t}}{\hat{\sigma_{k}}},
$$

where $\mathrm{A}_{k, t}$ is the actual announcement, $\mathrm{E}_{k, t}$ is the median forecast for news $k$ on day $t$, and $\hat{\sigma_{k}}$ is the standard deviation of $\mathrm{A}_{k, t}-\mathrm{E}_{k, t}, t=1,2, \ldots, T$.

\section{B. Jump Test}

A number of statistical tests have been proposed in recent literature to detect whether there are jumps in asset prices. For instance, Aït-Sahalia (2002) exploits the restrictions on the transition density of diffusion processes to assess the likelihood of jumps. Carr and Wu (2003) make use of the decay of the time value of an option with respect to the option's maturity. Barndorff-Nielsen and Shephard (2004), (2006) propose a bipower variation (BPV) measure to separate the jump variance and the diffusive variance. Lee and Mykland (2008) exploit the properties of BPV and develop a rolling-based nonparametric test of jumps. Aït-Sahalia and Jacod (2009) propose a family of statistical tests of jumps using power variations of returns. Jiang and Oomen (2008) propose a jump test based on the idea of "variance swap" and explicitly take into account market microstructure noise.

The jump test employed in our study is a combination of the Jiang and Oomen (2008) variance swap test along with the Barndorff-Nielsen and Shephard 


\section{TABLE 2}

\section{Macroeconomic News with Prescheduled Announcements}

Table 2 reports the list of macroeconomic news included in our analysis. $N$ denotes the total number of announcements during the period from January 5, 2004 to June 29, 2007; Day and Time denote, respectively, the weekday or day of the month and time (ET) of announcement; $\sigma$ SUR denotes the standard deviation of announcement surprises; $N_{|S U R|}>k \sigma$ SUR denotes the number of announcements where the announcement surprise is more than $k$ standard deviations. ${ }^{a}$ Business Inventories are announced at either 8:30 AM or 10:00 AM. During January 5, 2004 to June 29, 2007, there are 13 announcements at 8:30 AM and 29 announcements at 10:00 AM. ${ }^{\text {b }}$ Testimony of Economic Outlook was released at 14:30 on June 5, 2006

\begin{tabular}{|c|c|c|c|c|c|c|}
\hline News/Event & $N$ & Day & Time & $\sigma_{\text {SUR }}$ & $\begin{array}{l}N_{|S U R|}> \\
\sigma_{\text {SUR }} \\
\end{array}$ & $\begin{array}{l}N_{\mid \text {SUR } \mid>} \\
2 \sigma_{\text {SUR }} \\
\end{array}$ \\
\hline ADP payrolls & 14 & $\begin{array}{l}2 \text { days before change in nonfarm } \\
\text { payrolls }\end{array}$ & $8: 15$ & n.a. & n.a. & n.a. \\
\hline Business inventories & 42 & Around the 15th of the month & $8: 30 / 10: 00^{a}$ & 0.002266 & 10 & 2 \\
\hline Capacity utilization & 42 & 2 weeks after month-end & 9:15 & 0.00337 & 12 & 2 \\
\hline Change in nonfarm payrolls & 42 & 1st Friday of the month & $8: 30$ & 78.29956 & 14 & 3 \\
\hline Chicago PMI & 42 & Last business day of the month & 10:00 & 5.102023 & 13 & 3 \\
\hline Construction spending & 43 & 2 weeks after month-end & 10:00 & 0.183016 & 1 & 1 \\
\hline Consumer confidence & 42 & Last Tuesday of the month & $10: 00$ & 4.663151 & 13 & 1 \\
\hline Consumer credit & 42 & 5th business day of the month & $15: 00$ & 95.65377 & 1 & 1 \\
\hline Consumer price index & 42 & Around the 13th of the month & $8: 30$ & 0.001507 & 16 & 0 \\
\hline Current account & 14 & $10-11$ weeks after quarter-end & $8: 30$ & 7.554709 & 5 & 0 \\
\hline Durable orders & 42 & Around the 26th of the month & $8: 30$ & 0.026315 & 14 & 2 \\
\hline Economic outlook & 10 & According to schedule & $10: 00^{b}$ & n.a. & n.a. & n.a. \\
\hline Existing home sales & 41 & 25th of the month & $10: 00$ & 0.194676 & 14 & 3 \\
\hline Factory orders & 42 & $\begin{array}{l}\text { Around the 1st business day of the } \\
\text { month }\end{array}$ & $10: 00$ & 0.007144 & 10 & 3 \\
\hline FOMC minutes & 29 & $\begin{array}{l}\text { Thursday following the next FOMC } \\
\text { meeting date }\end{array}$ & $14: 00$ & n.a. & n.a. & n.a. \\
\hline $\begin{array}{l}\text { FOMC rate decision } \\
\text { expected }\end{array}$ & 28 & According to schedule & $14: 15$ & 0 & 0 & 0 \\
\hline $\begin{array}{l}\text { GDP (gross domestic } \\
\text { product) advance }\end{array}$ & 14 & $\begin{array}{l}\text { 3rd/4th week of the month for prior } \\
\text { quarter }\end{array}$ & $8: 30$ & 0.006236 & 6 & 3 \\
\hline GDP final & 14 & $\begin{array}{l}3 \mathrm{rd} / 4 \text { th week of } 2 \text { nd month following } \\
\text { the quarter }\end{array}$ & $8: 30$ & 0.004804 & 2 & 1 \\
\hline GDP preliminary & 14 & $\begin{array}{l}\text { 3rd/4th week of } 1 \text { st month following } \\
\text { the quarter }\end{array}$ & $8: 30$ & 0.004605 & 2 & 1 \\
\hline Housing starts & 42 & 2 or 3 weeks after the reporting month & $8: 30$ & 113.2129 & 10 & 4 \\
\hline Industrial production & 42 & Around the 15th of the month & $9: 15$ & 0.003494 & 16 & 2 \\
\hline Initial jobless claims & 182 & Thursday weekly & $8: 30$ & 16.29753 & 47 & 9 \\
\hline ISM index & 42 & 1st business day of the month & $10: 00$ & 2.230697 & 13 & 1 \\
\hline ISM services & 42 & 3rd business day of the month & $10: 00$ & 3.209909 & 16 & 1 \\
\hline Leading indicators & 42 & $\begin{array}{l}\text { Around the 1st few business days } \\
\text { of the month }\end{array}$ & $8: 30$ & 0.001612 & 10 & 2 \\
\hline Monthly Treasury budget & 42 & About the 3rd week of the month & $14: 00$ & 4.263603 & 6 & 3 \\
\hline New home sales & 42 & $\begin{array}{l}\text { Around the last business day of } \\
\text { the month }\end{array}$ & $10: 00$ & 97.96987 & 12 & 3 \\
\hline NY Empire State index & 42 & 15th/16th of the month & $8: 30$ & 9.61699 & 17 & 2 \\
\hline $\begin{array}{l}\text { Personal consumption } \\
\text { expenditure }\end{array}$ & 42 & $\begin{array}{l}\text { Around the 1st business day of } \\
\text { the month }\end{array}$ & $8: 30$ & 0.034868 & 5 & 5 \\
\hline Personal income & 42 & $\begin{array}{l}\text { Around the 1st business day of } \\
\text { the month }\end{array}$ & $8: 30$ & 0.003042 & 5 & 2 \\
\hline Philadelphia Fed index & 42 & 3rd Thursday of the month & $12: 00$ & 7.562973 & 17 & 1 \\
\hline Producer price index & 42 & Around the 11th of each month & $8: 30$ & 0.23078 & 2 & 2 \\
\hline Retail sales & 42 & Around the 12th of the month & $8: 30$ & 0.121455 & 2 & 2 \\
\hline Semiannual monetary policy rep & 7 & February and July annually & $10: 00$ & n.a. & n.a. & n.a. \\
\hline Trade balance & 42 & Around the 20th of the month & $8: 30$ & 3.358122 & 12 & 2 \\
\hline
\end{tabular}

(2006) BPV test. Both tests are derived in a model-free framework and apply to a very general asset price process. The tests are designed to detect the presence of jumps during a particular time period, for example, a day, using high-frequency data. Throughout the paper, we assume that bond prices are observed at regular time intervals, $\delta=1 / N$, over period $[0,1]$. The conventional realized variance $(\mathrm{RV})$ is defined as

$$
\mathrm{RV}_{N}=\sum_{i=1}^{N} r_{\delta, i}^{2}
$$


where $r_{\delta, j}=\ln \left(S_{j \delta} / S_{(j-1) \delta}\right)$. It is well known (see, e.g., Jacod and Shiryaev (1987), Andersen, Bollerslev, Diebold, and Labys (2003)) that $\operatorname{plim}_{N \rightarrow \infty} \mathrm{RV}_{N}=$ $V_{(0,1)}+\int_{0}^{1} J_{u}^{2} d q_{u}$, where $V_{(0,1)} \equiv \int_{0}^{1} V_{u} d u$. Put into words, RV is a consistent estimator of the total variance, including both the continuous diffusive component and the discontinuous jump component.

The BPV measure defined in normalized form is given by

$$
\mathrm{BPV}_{N}=\frac{1}{\mu_{1}^{2}} \sum_{i=1}^{N-1}\left|r_{\delta, i+1}\right|\left|r_{\delta, i}\right|
$$

where $\mu_{p}=2^{p / 2} \Gamma((p+1) / 2) / \sqrt{\pi}$ for $p>0$. Barndorff-Nielsen and Shephard (2006) show that $\operatorname{plim}_{N \rightarrow \infty} \mathrm{BPV}_{N}=V_{(0,1)}$, that is, the BPV captures the diffusive variance component, and they propose the following jump test based on the difference between RV and BPV:

$$
\frac{V_{(0,1)} \sqrt{N}}{\sqrt{\Omega_{\mathrm{BPV}}}}\left(1-\frac{\mathrm{BPV}_{N}}{\mathrm{RV}_{N}}\right) \stackrel{d}{\longrightarrow} \mathcal{N}(0,1),
$$

where $\Omega_{\mathrm{BPV}}=\left(\pi^{2} / 4+\pi-5\right) Q_{(0,1)}$ and $Q_{(0,1)}=\int_{0}^{1} V_{u}^{2} d u$.

The variance swap measure (SWV) in Jiang and Oomen (2008) is constructed as follows:

$$
\mathrm{SWV}_{N}=2 \sum_{j=1}^{N}\left(R_{\delta, j}-r_{\delta, j}\right)=2 \sum_{j=1}^{N} R_{\delta, j}-2 \ln \left(S_{1} / S_{0}\right)
$$

where $R_{\delta, j}=\left(S_{j \delta}-S_{(j-1) \delta}\right) / S_{(j-1) \delta}$. Based on the difference between RV and $\mathrm{SWV}$, the variance swap jump test is proposed as follows:

$$
\frac{V_{(0,1)} N}{\sqrt{\Omega_{\mathrm{SWV}}}}\left(1-\frac{\mathrm{RV}_{N}}{\mathrm{SWV}_{N}}\right) \stackrel{d}{\longrightarrow} \mathcal{N}(0,1),
$$

where $\Omega_{\mathrm{SWV}}=(1 / 9) \mu_{6} X_{(0,1)}$ and $X_{(0,1)}=\int_{0}^{T} V_{u}^{3} d u$.

When the test statistics of both the BPV and SWV approaches are significant (at the $1 \%$ critical level), we reject the null hypothesis of no jumps. We then follow a sequential approach to identify jump returns. As acknowledged in the literature, pinpointing exactly which return is a jump is a difficult task. This is because volatility is time varying and clustered, and returns of the largest magnitude are not necessarily jumps. In this paper, we propose a sequential approach to identify jump returns. Details of the procedure are given in Appendix A. In a concurrent study, Andersen, Bollerslev, Frederiksen, and Nielsen (2010) propose a similar procedure for identifying intraday jump returns. In addition, since high-frequency intraday returns are used, the data are likely subject to significant market microstructure effects. In both jump testing and jump return identification, we take into account potential market microstructure effects. Specifically, in the first step we allow for measurement error (i.e., asset price is observed with noise) in the SWV test, whereas in the second step we take into account discrete price changes due to tick size and bid-ask spread. Details can be found in Appendix A. 
We evaluate the performance of jump tests using simulations. The design of the simulation is described in detail in Appendix B. The results indicate that both the BPV and SWV tests tend to overreject the null hypothesis of no jumps. The joint test, on the other hand, has better size properties. As expected, the combined test has lower power. However, when the jump size is large (more than 4 times the return standard deviation), the joint test procedure does not sacrifice much of the power and works well in picking up large jumps. A conservative test such as this suits our purpose, as we are interested in large price changes in the U.S. Treasury security market.

\section{Empirical Results}

In this section, we first present summary statistics of identified jumps and then examine how often jumps are associated with prescheduled news announcements/events.

\section{A. Jumps in Bond Prices}

Table 3 reports the jump frequency, the statistics of jump size for different maturities, and the number of concurrent jumps across maturities. Among the

\section{TABLE 3}

Summary Statistics of Bond Price Jumps

\begin{tabular}{|c|c|c|c|c|c|c|c|c|c|c|}
\hline Bond & $N_{d}$ & $N$ & Mean & Mean (abs.) & $\underline{\text { Median (abs.) }}$ & Max. & Min. & $\underline{\text { Std. Dev. }}$ & $\underline{\text { Skewness }}$ & Kurtosis \\
\hline \multicolumn{11}{|c|}{ Panel A. All Jumps } \\
\hline $\begin{array}{l}\text { 2-year note } \\
\text { 3-year note } \\
5 \text {-year note } \\
\text { 10-year note } \\
\text { 30-year bond }\end{array}$ & $\begin{array}{r}100 \\
101 \\
105 \\
97 \\
102\end{array}$ & $\begin{array}{l}120 \\
115 \\
118 \\
106 \\
113\end{array}$ & $\begin{array}{r}-0.01 \\
0.00 \\
0.00 \\
-0.01 \\
-0.08\end{array}$ & $\begin{array}{l}0.09 \\
0.14 \\
0.18 \\
0.31 \\
0.53\end{array}$ & $\begin{array}{l}0.06 \\
0.10 \\
0.14 \\
0.24 \\
0.40\end{array}$ & $\begin{array}{l}0.37 \\
0.74 \\
1.12 \\
1.48 \\
2.13\end{array}$ & $\begin{array}{l}-0.53 \\
-0.67 \\
-0.87 \\
-1.53 \\
-3.55\end{array}$ & $\begin{array}{l}0.11 \\
0.18 \\
0.23 \\
0.38 \\
0.70\end{array}$ & $\begin{array}{r}-0.38 \\
-0.11 \\
0.76 \\
0.27 \\
-0.56\end{array}$ & $\begin{array}{l}7.35 \\
6.51 \\
7.55 \\
6.32 \\
8.34\end{array}$ \\
\hline \multicolumn{11}{|c|}{ Panel B. Positive Jumps } \\
\hline $\begin{array}{l}\text { 2-year note } \\
\text { 3-year note } \\
5 \text {-year note } \\
\text { 10-year note } \\
\text { 30-year bond }\end{array}$ & $\begin{array}{l}47 \\
58 \\
48 \\
47 \\
45\end{array}$ & $\begin{array}{l}51 \\
60 \\
51 \\
48 \\
46\end{array}$ & $\begin{array}{l}0.09 \\
0.14 \\
0.21 \\
0.32 \\
0.55\end{array}$ & $\begin{array}{l}0.09 \\
0.14 \\
0.21 \\
0.32 \\
0.55\end{array}$ & $\begin{array}{l}0.06 \\
0.11 \\
0.15 \\
0.25 \\
0.41\end{array}$ & $\begin{array}{l}0.37 \\
0.74 \\
1.12 \\
1.48 \\
2.13\end{array}$ & $\begin{array}{l}0.04 \\
0.05 \\
0.08 \\
0.12 \\
0.22\end{array}$ & $\begin{array}{l}0.07 \\
0.11 \\
0.17 \\
0.25 \\
0.43\end{array}$ & $\begin{array}{l}2.06 \\
3.59 \\
3.52 \\
2.95 \\
2.32\end{array}$ & $\begin{array}{r}7.36 \\
19.02 \\
17.80 \\
12.37 \\
8.57\end{array}$ \\
\hline \multicolumn{11}{|c|}{ Panel C. Negative Jumps } \\
\hline $\begin{array}{l}\text { 2-year note } \\
\text { 3-year note } \\
5 \text {-year note } \\
\text { 10-year note } \\
\text { 30-year bond }\end{array}$ & $\begin{array}{l}61 \\
52 \\
61 \\
53 \\
61\end{array}$ & $\begin{array}{l}69 \\
55 \\
67 \\
58 \\
67\end{array}$ & $\begin{array}{l}-0.08 \\
-0.14 \\
-0.16 \\
-0.29 \\
-0.52\end{array}$ & $\begin{array}{l}0.08 \\
0.14 \\
0.16 \\
0.29 \\
0.52\end{array}$ & $\begin{array}{l}0.06 \\
0.10 \\
0.13 \\
0.23 \\
0.40\end{array}$ & $\begin{array}{l}-0.04 \\
-0.05 \\
-0.07 \\
-0.14 \\
-0.21\end{array}$ & $\begin{array}{l}-0.53 \\
-0.67 \\
-0.87 \\
-1.53 \\
-3.55\end{array}$ & $\begin{array}{l}0.07 \\
0.12 \\
0.12 \\
0.21 \\
0.49\end{array}$ & $\begin{array}{l}-4.16 \\
-2.79 \\
-3.53 \\
-4.09 \\
-4.16\end{array}$ & $\begin{array}{l}23.30 \\
11.31 \\
19.66 \\
23.55 \\
24.01\end{array}$ \\
\hline Bond & \multicolumn{3}{|c|}{ 2-Year Note } & \multicolumn{3}{|c|}{$\underline{5-Y e a r ~ N o t e}$} & \multicolumn{2}{|c|}{$\underline{10-Y e a r \text { Note }}$} & \multicolumn{2}{|c|}{ 30-Year Bond } \\
\hline \multicolumn{11}{|c|}{ Panel D. Concurrent Jumps across Maturities } \\
\hline $\begin{array}{l}\text { 2-year note } \\
\text { 3-year note } \\
5 \text {-year note } \\
\text { 10-year note } \\
30 \text {-year bond }\end{array}$ & & $\begin{array}{r}12 \\
6 \\
5\end{array}$ & $\begin{array}{l}0 \\
3 \\
6 \\
9 \\
4\end{array}$ & $\begin{array}{r}115 \\
74 \\
62 \\
50\end{array}$ & & $\begin{array}{l}18 \\
68 \\
57\end{array}$ & & $\begin{array}{r}106 \\
67\end{array}$ & & 113 \\
\hline
\end{tabular}


5 securities, the 2-year note has the highest jump frequency with 120 jumps, followed by the 5-year note with 118 jumps and the 3-year note with 115 jumps. The jump size generally increases with maturity, and the mean absolute jump size goes up monotonically from $0.09 \%$ for the 2 -year note to $0.53 \%$ for the 30 -year bond. This pattern is consistent with Balduzzi et al. (2001), who find that the size of a price change as a result of announcement surprise is increasing with maturity. Compared to daily return volatility reported in Table 1, jumps represent dramatic price changes over 5-minute intervals. Separating positive jumps from negative jumps, there are overall more negative jumps than positive jumps. The asymmetric pattern is consistent with Lahaye, Laurent, and Neely (2011), who find similar asymmetry in 30-year bond futures.

How often do jumps happen at the same time across different maturities? Panel D of Table 3 shows the concurrent jumps across maturities. Jumps across 2 different maturities are defined as concurrent if they are less than 10 minutes apart. Consistent with Dungey, MacKenzie, and Smith (2009), the results indicate that bond prices of different maturities often jump together. For example, out of the 120 jumps at the 2-year maturity, about $60 \%$ have concurrent jumps at the 3 -year maturity. We note that here we simply document whether jumps across maturities are close to each other in time. The issue of co-jumps is formally examined in Dungey et al. and Lahaye et al. (2011). Dungey et al. examine co-jumps across maturities using the eSpeed data. Lahaye et al. examine co-jumps across asset markets.

\section{B. Jumps and Macroeconomic News Announcements}

We further examine how often jumps are associated with prescheduled news announcements. A jump is identified as associated with a news announcement if it is within 10 minutes of prescheduled announcement time. With a 10-minute window, we allow for potential errors (such as recording errors) in announcement time.

Table 4 indicates that a large majority of jumps occurs during the time of announcement. For example, more than $90 \%$ of jumps of the 2-year note occur during prescheduled announcements. The results of other notes are similar except for the 30-year bond, which has a higher proportion of jumps outside announcement times. Panels $C$ and D report the frequency of concurrent jumps across maturities. As expected, for jumps occurring at announcement times the frequency of concurrent jumps is higher.

The left-hand column of Figure 1 plots the distribution of the jump frequency throughout the day for the most liquid 2-, 5-, and 10-year notes. The frequency spikes around 8:30, 10:00, and 14:00, corresponding to standard prescheduled announcement times. The right-hand column plots the distribution of jumps occurring outside announcement times. The distribution is, in general, flat over the day, conforming to the intuition that these jumps are generally unanticipated.

To pinpoint exactly what drives jumps in bond prices, we first focus on jumps occurring at announcement times. Panel A of Table 5 reports the top 15 announcements associated with the largest number of jumps. Among the top of the list are: initial jobless claims, change in nonfarm payrolls, consumer price 
TABLE 4

Jumps and Prescheduled News Announcements

Panels $\mathrm{A}$ and $\mathrm{B}$ of Table 4 report the number of jumps, $N$, and summary statistics of jumps associated with a prescheduled news announcement and those not directly associated with a prescheduled news announcement. A jump is referred to as associated with a news announcement if it is within 10 minutes of a prescheduled news announcement time. Panels $C$ and $\mathrm{D}$ report the number of concurrent jumps across maturities, where concurrent jumps are defined in the same way as in Table 3.

\begin{tabular}{|c|c|c|c|c|c|c|c|c|c|c|}
\hline Bond & $\underline{N_{d}}$ & $N$ & Mean & Mean (abs.) & $\underline{\text { Median (abs.) }}$ & Max. & Min. & $\underline{\text { Std. Dev. }}$ & Skewness & Kurtosis \\
\hline \multicolumn{11}{|c|}{ Panel A. Jumps Associated with Prescheduled Announcement } \\
\hline 2-year note & 92 & 109 & -0.01 & 0.09 & 0.06 & 0.37 & -0.53 & 0.11 & -0.40 & 6.96 \\
\hline 3-year note & 95 & 108 & 0.00 & 0.14 & 0.10 & 0.74 & -0.67 & 0.18 & -0.13 & 6.36 \\
\hline 5 -year note & 97 & 107 & 0.01 & 0.19 & 0.14 & 1.12 & -0.87 & 0.24 & 0.65 & 7.12 \\
\hline 10-year note & 87 & 96 & -0.01 & 0.31 & 0.24 & 1.48 & -1.53 & 0.39 & 0.24 & 6.13 \\
\hline 30-year bond & 84 & 89 & -0.06 & 0.54 & 0.42 & 2.13 & -1.71 & 0.64 & 0.27 & 3.94 \\
\hline \multicolumn{11}{|c|}{ Panel B. Jumps Not Associated with Prescheduled Announcement } \\
\hline 2-year note & 11 & 11 & -0.02 & 0.05 & 0.05 & 0.07 & -0.09 & 0.05 & 0.35 & 1.65 \\
\hline 3-year note & 7 & 7 & -0.02 & 0.10 & 0.09 & 0.12 & -0.14 & 0.10 & 0.26 & 1.25 \\
\hline 5 -year note & 11 & 11 & -0.09 & 0.12 & 0.12 & 0.18 & -0.18 & 0.09 & 2.37 & 7.68 \\
\hline 10-year note & 11 & 11 & -0.03 & 0.23 & 0.22 & 0.35 & -0.35 & 0.24 & 0.26 & 1.45 \\
\hline 30-year bond & 23 & 24 & -0.17 & 0.52 & 0.27 & 2.13 & -3.55 & 0.89 & -1.53 & 10.69 \\
\hline Bond & & \multicolumn{2}{|c|}{ 2-Year Note } & 3-Year $N$ & \multicolumn{2}{|c|}{ 5-Year Note } & \multicolumn{2}{|c|}{ 10-Year Note } & \multicolumn{2}{|c|}{ 30-Year Bond } \\
\hline
\end{tabular}

Panel C. Concurrent Jumps Associated with Prescheduled Announcement

$\begin{array}{lrr}\text { 2-year note } & 109 & \\ \text { 3-year note } & 70 & 708 \\ \text { 5-year note } & 62 & 60 \\ \text { 10-year note } & 56 & 49 \\ \text { 30-year bond } & 43 & \end{array}$

$\begin{array}{rr}08 & \\ 70 & 107 \\ 60 & 63 \\ 49 & 54\end{array}$

Panel D. Concurrent Jumps Not Associated with Prescheduled Announcement

2-year note

3-year note

5-year note

10-year note

30-year bond

11
3
4
3
1

$\begin{array}{rr}7 & \\ 4 & 11 \\ 2 & 5 \\ 1 & 3\end{array}$

95

60
89

index, retail sales, housing starts, producer price index, FOMC rate decision expected, and ISM index. These announcements are generally consistent with those considered in the existing literature, such as Balduzzi et al. (2001), Green (2004), Pasquariello and Vega (2007), and Menkveld et al. (2010). In addition, we identify news items that have not been examined in the previous studies but are potential causes of jumps in bond prices. They include the announcement of NY Empire State Index, ISM service, Chicago PMI, existing home sales, Philadelphia Fed Index, ADP National Employment Report, and the release of the testimony of the Semiannual Monetary Policy Report and Economic Outlook.

Is announcement surprise indicative of jumps? The existing literature documents that a larger surprise tends to have a bigger impact on bond prices. In this paper, we focus on jumps in bond prices and are interested in how much explanatory power announcement surprise has for jumps. We sort jumps on announcement days to form 5 equal groups (quintiles) according to the absolute jump return and examine the patterns of announcement surprises across groups. Panel B of Table 5 reports the mean absolute jump return, the mean absolute announcement surprise, and the number of significant announcement surprises (i.e., absolute survey error larger than 1 standard deviation) for each group. When multiple news announcements are associated with a jump, news with the biggest announcement surprise is used in the calculation of average announcement surprise. 
FIGURE 1

Intraday Frequency of Jumps

Figure 1 plots the intraday distribution of jump frequency (number of jumps over each 5-minute interval) for the 2-, 5-, and 10 -year notes. The intraday distribution of jump frequency is plotted for all jumps as well as jumps outside prescheduled news announcement times.

Graph A. All Jumps (2-year note)

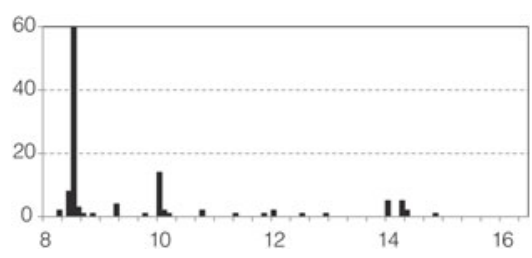

Graph C. All Jumps (5-year note)

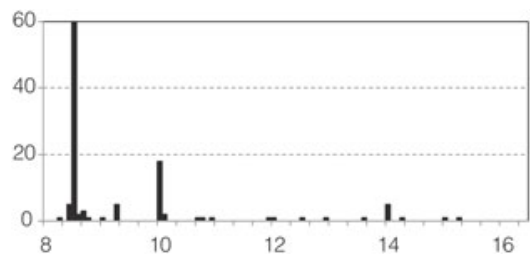

Graph E. All Jumps (10-year note)

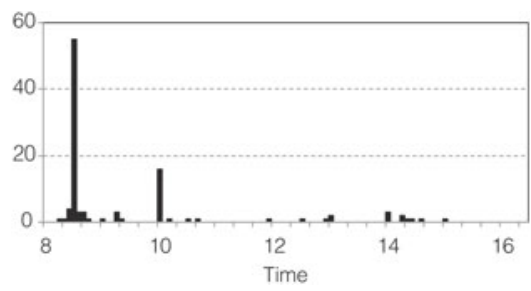

Graph B. Jumps with No News (2-year note)

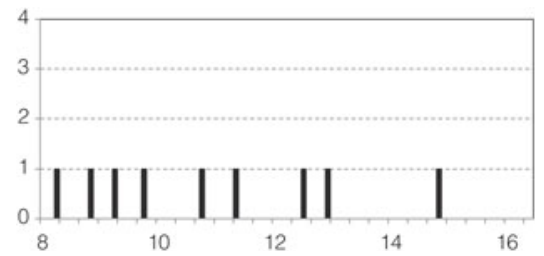

Graph D. Jumps with No News (5-year note)

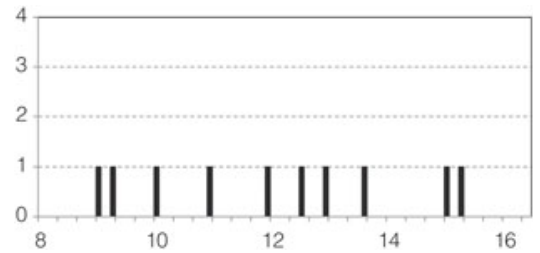

Graph F. Jumps with No News (10-year note)

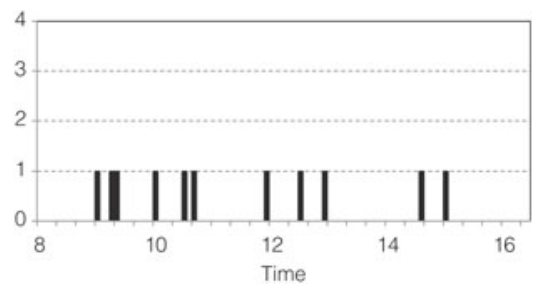

The results show a rather nonmonotonic relation between announcement surprise and jump magnitude. That is, the group with higher jump return does not necessarily have higher announcement surprises. The finding is evidence that announcement surprise has limited power in explaining jumps.

Now, we turn to jumps outside announcement times. Results in Table 4 indicate that although the number of jumps outside announcement times is relatively small, the median jump sizes are overall comparable to those at prescheduled announcement times. While these jumps could be attributed to unexpected information arrival or liquidity shocks in general, it turns out that to pinpoint the exact cause, even as an ex post check, is not always so straightforward. For each of the jumps, we search the news archive FACTIVA for potentially related news/events. ${ }^{5}$ Below are 4 jumps of the 10-year note.

02/28/2005: 10 -year note slid 22/32 in price, driving yields up to $4.36 \%$ from $4.27 \%$. No specific news found.

${ }^{5}$ FACTIVA offers a comprehensive news collection from The Wall Street Journal, Financial Times, Dow Jones, Reuters, and the Associated Press. 


\section{TABLE 5}

Jumps, Macroeconomic News, and Announcement Surprises

Panel A of Table 5 reports the top 15 news announcements with the largest number of jumps. It reports the number of jumps $\left(N_{J}\right)$ and mean absolute jump return $\left(\left|R E T_{J}\right|\right)$ associated with each news item. Total $N_{J}$ is the total number of unique jumps (excluding concurrent jumps) among all maturities. In Panel B, we sort jumps in each maturity into 5 groups (quintiles) according to absolute jump return. For each group, we then calculate and report the mean absolute jump return (|RETJ|), mean absolute surprise $|S U R|$, and number of significant announcement surprises $\left(N^{*}\right)$.

Panel A. Macroeconomic News and Jumps

\begin{tabular}{|c|c|c|c|c|c|c|c|c|c|c|c|}
\hline \multirow[b]{2}{*}{ News/Event } & \multicolumn{2}{|c|}{$\begin{array}{c}\text { 2-Year } \\
\text { Note }\end{array}$} & \multicolumn{2}{|c|}{$\begin{array}{c}\text { 3-Year } \\
\text { Note }\end{array}$} & \multicolumn{2}{|c|}{$\begin{array}{c}\text { 5-Year } \\
\text { Note }\end{array}$} & \multicolumn{2}{|c|}{$\begin{array}{c}\text { 10-Year } \\
\text { Note }\end{array}$} & \multicolumn{2}{|c|}{$\begin{array}{c}\text { 30-Year } \\
\text { Bond }\end{array}$} & \multirow[b]{2}{*}{$\underline{\text { Total } N_{J}}$} \\
\hline & $N_{J}$ & $\mid$ RETJ| & $\underline{N}$ & $\mid$ RETJ| & $\underline{N_{J}}$ & $\mid$ RETJ| & $\underline{N}$ & $\mid$ RETJ| & $N_{J}$ & $\mid$ RETJ| & \\
\hline Initial jobless claims & 16 & 0.05 & 9 & 0.09 & 14 & 0.14 & 11 & 0.22 & 8 & 0.42 & 27 \\
\hline Change in nonfarm payrolls & 26 & 0.18 & 24 & 0.29 & 18 & 0.39 & 19 & 0.57 & 18 & 0.99 & 25 \\
\hline Consumer price index & 17 & 0.07 & 18 & 0.14 & 19 & 0.21 & 14 & 0.31 & 15 & 0.52 & 25 \\
\hline Retail sales & 13 & 0.08 & 13 & 0.11 & 8 & 0.19 & 14 & 0.26 & 8 & 0.43 & 17 \\
\hline Housing starts & 4 & 0.06 & 7 & 0.12 & 9 & 0.15 & 5 & 0.23 & 5 & 0.47 & 14 \\
\hline Producer price index & 6 & 0.07 & 6 & 0.10 & 9 & 0.18 & 5 & 0.33 & 8 & 0.46 & 13 \\
\hline FOMC rate decision expected & 6 & 0.08 & 5 & 0.12 & 0 & n.a. & 4 & 0.25 & 4 & 0.78 & 12 \\
\hline ISM index & 5 & 0.06 & 8 & 0.09 & 7 & 0.14 & 7 & 0.24 & 9 & 0.37 & 12 \\
\hline Construction spending & 4 & 0.06 & 6 & 0.09 & 7 & 0.14 & 6 & 0.24 & 8 & 0.36 & 11 \\
\hline Durable orders & 5 & 0.06 & 4 & 0.11 & 9 & 0.15 & 5 & 0.28 & 6 & 0.47 & 11 \\
\hline Consumer confidence & 3 & 0.05 & 3 & 0.07 & 5 & 0.11 & 4 & 0.25 & 6 & 0.37 & 9 \\
\hline NY Empire State index & 6 & 0.05 & 5 & 0.11 & 7 & 0.21 & 8 & 0.26 & 6 & 0.50 & 9 \\
\hline New home sales & 6 & 0.05 & 5 & 0.07 & 7 & 0.12 & 4 & 0.22 & 3 & 0.35 & 9 \\
\hline GDP advance & 2 & 0.09 & 4 & 0.10 & 4 & 0.14 & 4 & 0.23 & 4 & 0.39 & 7 \\
\hline ISM services & 2 & 0.04 & 4 & 0.09 & 1 & 0.09 & 3 & 0.16 & 2 & 0.30 & 7 \\
\hline
\end{tabular}

Panel B. Jumps and Announcement Surprises

\begin{tabular}{|c|c|c|c|c|c|c|c|c|c|c|c|c|c|c|c|}
\hline \multirow[b]{2}{*}{ Quintiles } & \multicolumn{3}{|c|}{ 2-Year Note } & \multicolumn{3}{|c|}{ 3-Year Note } & \multicolumn{3}{|c|}{ 5-Year Note } & \multicolumn{3}{|c|}{ 10-Year Note } & \multicolumn{3}{|c|}{ 30-Year Bond } \\
\hline & $\underline{|R E T J|}$ & $\underline{\text { SUR }}$ & $N^{*}$ & $\underline{|R E T J|}$ & $\underline{|S U R|}$ & $N^{*}$ & $\underline{|R E T \jmath|}$ & $\underline{|S U R|}$ & $N^{*}$ & $\underline{|R E T J|}$ & $\underline{|S U R|}$ & $\underline{N^{*}}$ & $\underline{|R E T J|}$ & $\underline{|S U R|}$ & $N^{*}$ \\
\hline & 0.038 & & 8 & 062 & & 5 & 0 & & 8 & & & 7 & & 00 & 6 \\
\hline Q2 & 0.049 & 0.756 & 3 & 0.082 & 0.900 & 7 & 0. & & 8 & 4 & & 5 & 20 & 76 & 6 \\
\hline Q3 & 0.062 & & 9 & & & 8 & & & 7 & & & 9 & & & 8 \\
\hline Q4 & 0.082 & 0.896 & 7 & 0.147 & 0.693 & 5 & 0.201 & 1.116 & 8 & 0.324 & 0.959 & 5 & 0.547 & 0.890 & 4 \\
\hline Q5 (high) & 0.221 & 1.069 & 8 & 0.294 & 0.983 & 8 & 0.409 & 0.900 & 9 & 0.709 & 0.963 & 8 & 0.873 & 1.003 & 9 \\
\hline
\end{tabular}

05/04/2005: Longer-dated Treasury prices plummeted after the government startled investors by saying it was considering resuming issuance of 30 -year bonds.

03/28/2006: U.S. T-bond investors digest a Federal Reserve policy statement, crafted with new Federal Reserve chairman Ben Bernanke, suggesting more interest rate hikes.

09/19/2006: Bond investors bet heavily on a Federal Reserve interest rate cut soon.

\section{Market Activities around Jumps}

In this section, we examine in more detail market activities around jumps. Figure 2 plots market activities around jumps in the 2-year note. The patterns for other maturities are similar and thus not reported. The left-hand column focuses on announcement days, contrasting days with jumps versus those without. For a clean comparison, we exclude announcement days with multiple jumps or jumps outside announcement times. The right-hand column plots market activities around jumps outside prescheduled announcement times. The findings are summarized below. 
The Announcement Effect. Consistent with Fleming and Remolona (1999), Balduzzi et al. (2001), and Green (2004), trading volume is low during the preannouncement period and increases sharply after the announcement. Consistent

FIGURE 2

\section{Market Activities around Jumps}

Figure 2 plots market activities of the 2-year note before and after jumps. The left-hand column contrasts market activities for macroeconomic announcements with jumps to those with no jumps. The right-hand column plots market activities around jumps outside prescheduled news announcement times. Variables include trading volume (\$millions), return volatility (\%), relative bid-ask spread $(\times 10,000)$, depth of the entire order book (\$millions), depth at the best bid and ask (\$millions), total hidden depth (\$millions), and hidden depth at the best bid and ask (\$millions).

Graph A. Trading Volume (news)

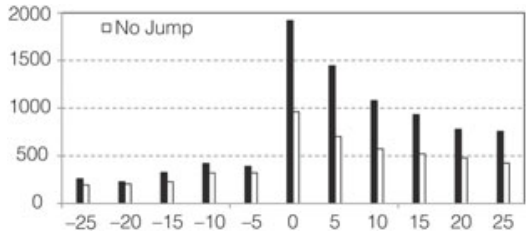

Graph C. Return Volatility (news)

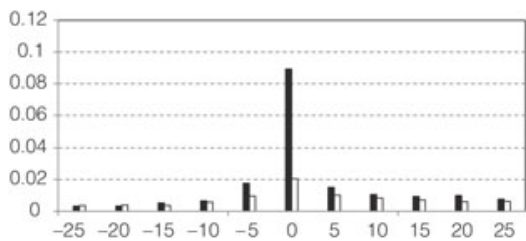

Graph E. Bid-Ask Spread (news)

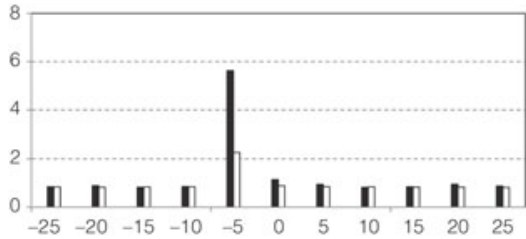

Graph G. Total Depth (news)

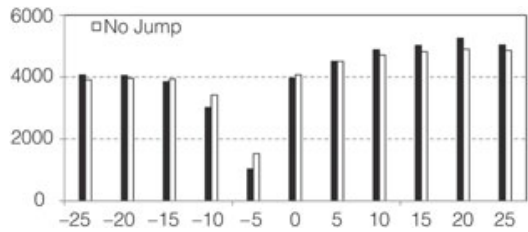

Graph I. Depth at Best Bid/Ask (news)

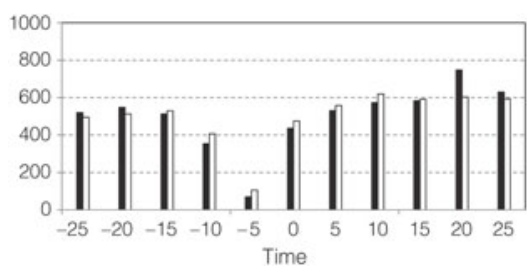

Graph B. Trading Volume (no news)

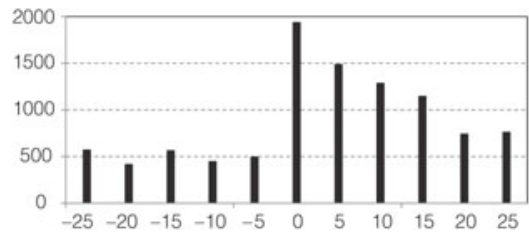

Graph D. Return Volatility (no news)

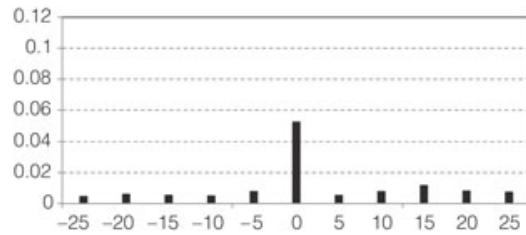

Graph F. Bid-Ask Spread (no news)

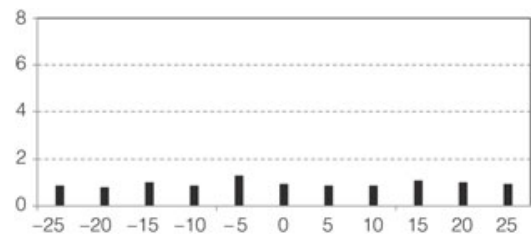

Graph H. Total Depth (no news)

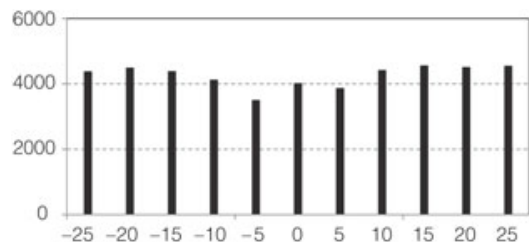

Graph J. Depth at Best Bid/Ask (no news)

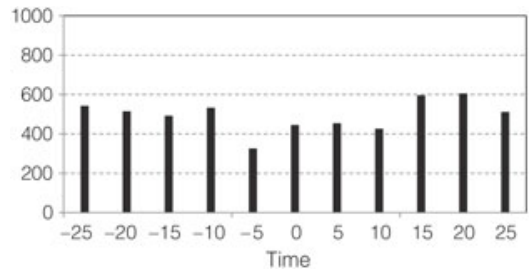

(continued on next page) 
FIGURE 2 (continued)

Market Activities around Jumps

Graph K. Total Hidden Depth (news)

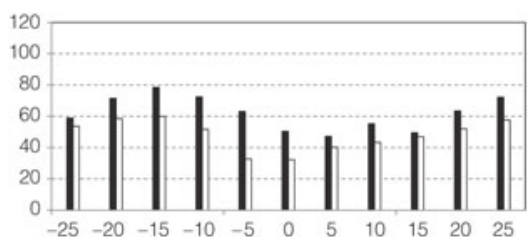

Graph M. Hidden Depth at Best B/A (news)

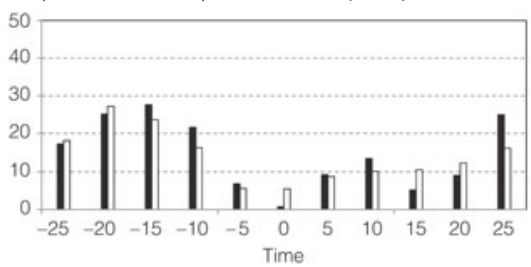

Graph L. Total Hidden Depth (no news)

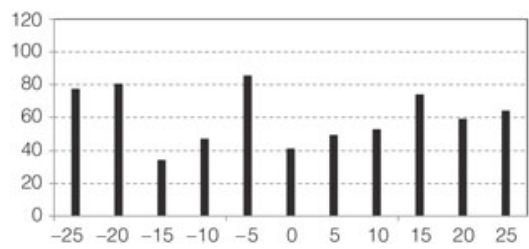

Graph N. Hidden Depth at Best B/A (no news)

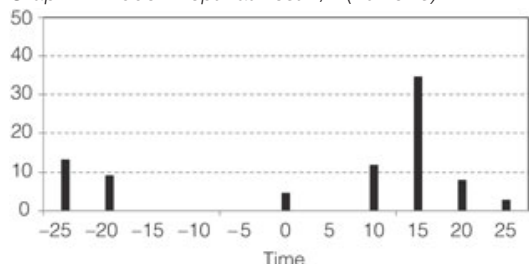

with findings in Fleming and Piazzesi (2006) on FOMC announcements, return volatility, defined as the average of absolute change in logarithmic price, starts to rise before announcements and peaks at the announcement time. Bid-ask spread increases before announcements. Both the depth at the best quotes and overall market depth drop to the lowest level prior to announcement and go back to the normal level afterwards. Hidden depth at the best quotes shows a similar pattern as the observed depth. The results suggest that market participants withdraw orders when facing information uncertainty.

The Jump Effect. When a jump occurs at an announcement time, the increase in trading volume is even more dramatic. Compared to announcements without jumps, trading volume around announcement times nearly doubles. Both the depth at the best quotes and overall market depth are lower during the preannouncement period on announcement days with jumps. Similarly, there is a more pronounced preannouncement increase in volatility and a widening of spread on days with jumps. This suggests that before jumps occur, market participants withdraw orders at the best quotes and place them further out. The widened bid-ask spread could lead to large price changes even without significant announcement surprises. This finding offers a plausible explanation for the imperfect relation between announcement surprises and price jumps.

Jumps Outside Announcement Time. Similar to jumps at announcement times, trading volume increases at jumps outside announcement times. However, in this case we do not observe any volatility increase prior to jumps. Also, the spread fluctuates around a stable level before and after jumps. This is further evidence that these jumps are triggered by unanticipated information shocks or events. Different from jumps at announcement times, market depth stays at a lower level after jumps outside announcement times. The complete withdrawal of hidden depth at 
the best quotes and the lower level of observed depth before these jumps may be a hint of information asymmetry in the U.S. Treasury market.

\section{Further Analysis}

\section{A. Information Shocks versus Liquidity Shocks}

The findings documented in the previous section suggest that preannouncement liquidity shocks may play an important role in bond price jumps. In this section, we assess the role of information shocks and liquidity shocks in price jumps. Again, information shocks are measured by announcement surprises. In our analysis, liquidity shock carries a broad meaning, and it could arise due to pure trading imbalance or order withdrawal. As discussed in Fleming and Piazzesi (2006), dealers tend to withdraw their orders to avoid being picked off in the upcoming information event. Motivated by findings on bid-ask spread and market depth before jumps, we define the following variables to capture liquidity shocks. Similar liquidity variables are used by Mizrach and Neely (2008), who find that relative liquidity between spot and futures markets predicts information shares.

Standardized Shock to Overall Depth (DPTHSHK $\left.K_{t-1}\right)$. It is defined as the difference between overall depth in the 5-minute interval prior to announcement $(t-1)$ and the mean of overall depth over intervals $t-6$ to $t-2$, scaled by its standard deviation:

$$
\text { DPTHSHK }_{t-1}=\frac{\text { DEPTH }_{t-1}-\frac{1}{5} \sum_{j=2}^{6} \mathrm{DEPTH}_{t-j}}{\sigma_{\text {DEPTH }}},
$$

where $\mathrm{DEPTH}_{t-j}$ is the overall observed market depth at the end of interval $t-j$. It captures the withdrawal of orders or the drop in overall observed market depth prior to announcements.

Standardized Shock to Spread (SPRDSHK $\left.K_{t-1}\right)$. It is defined as

$$
\operatorname{SPRDSHK}_{t-1}=\frac{\operatorname{SPREAD}_{t-1}-\frac{1}{5} \sum_{j=2}^{6} \operatorname{SPREAD}_{t-j}}{\sigma_{\mathrm{SPREAD}}},
$$

where $\mathrm{SPREAD}_{t-j}$ is the spread at the end of interval $t-j$. This measure captures the withdrawal of best quotes and thus changes in bid-ask spread prior to announcements.

Standardized Shock to Hidden Depth $\left(H I D S H K_{t-1}\right)$. It is defined similarly as the shock to observed depth and captures the withdrawal of hidden depth.

Realized Volatility $\left(V O L A_{t-1}\right)$. It is calculated as the square root of the sum of squared 5-minute log returns during the 30-minute interval before announcements. Realized volatility proxies for market uncertainty. In a recent study, Beber and Brandt (2009) construct a measure of macroeconomic uncertainty using prices of economic derivatives. Unfortunately, these prices are only available for selected news items, namely, change in nonfarm payrolls, retail sales, ISM, and initial jobless claims. 
Order Flow Imbalance $\left(O F_{t-1}\right)$. It is the difference between buy volume and sell volume during the 5-minute interval before announcements. As shown in previous literature, such as Evans (2002), Evans and Lyons (2002), Green (2004), and Brandt and Kavajecz (2004), order flow imbalance carries significant information of price change. Given that we are interested in whether information embedded in order flow predicts price change but not the direction of price change, we use the absolute value of order flow (scaled by its sample mean) in our analysis.

Order Imbalance $\left(\mathrm{OB}_{t-1}\right)$. It is calculated as $\mathrm{DEPTH}_{\mathrm{ASK}, t-1}-\mathrm{DEPTH}_{\mathrm{BID}, t-1}$ at the end of interval $t-1$. Order imbalance is shown to be informative about future price movements in Cao, Hansch, and Wang (2009) and Harris and Panchapagesan (2005). Similar to order flow imbalance, we use the absolute value of order imbalance (scaled by its sample mean) in our analysis.

To examine how announcement surprises and liquidity shocks contribute to the likelihood of jumps, we focus on announcement days. First, we estimate the following probit model to examine whether preannouncement liquidity shocks are predictive of jumps:

$$
\begin{aligned}
& P\left(\mathrm{JUMP}_{t} \mid \mathrm{ANNOUNCEMENT}\right)=f\left(\alpha+\beta_{\text {DPTHSHK } \text { DPTHSHK }_{t-1}}\right.
\end{aligned}
$$

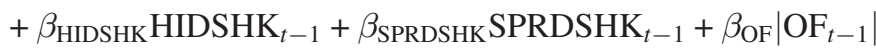

$$
\begin{aligned}
& \left.+\beta_{\mathrm{OB}}\left|\mathrm{OB}_{t-1}\right|+\beta_{\mathrm{VOLA}} \operatorname{VOLA}_{t-1}\right) \text {, }
\end{aligned}
$$

where $P(\cdot)$ denotes the probability that a jump occurs, which ex post takes a value of 1 when there is a jump at the announcement time $t$, and 0 otherwise. To keep the analysis clean, only announcement days with a single jump at the announcement time are included. The 1st set of columns in Table 6 reports the estimation results of the above model for 2-, 5-, and 10-year notes. Results for the 3-year note and the 30-year bond are similar and not reported for brevity. The null hypothesis that the coefficients of all liquidity variables are jointly 0 is strongly rejected for all maturities. In particular, realized volatility is significant at the $1 \%$ level, and shocks to spread and shocks to overall market depth are significant at the $10 \%$ level for all 5 maturities.

Next, we estimate a similar model with only information shocks to examine how well announcement surprises explain jumps:

$$
\left.P\left(\mathrm{JUMP}_{t} \mid \mathrm{ANNOUNCEMENT}\right)^{\mathrm{A}}\right)=f\left(\alpha+\Sigma_{j=1}^{J} \gamma_{j}\left|\mathrm{SUR}_{j, t}\right|\right),
$$

where $\left|\mathrm{SUR}_{j, t}\right|$ is the absolute value of the standardized announcement surprise for news item $j$, where $j=1,2, \ldots, J$. Note that while liquidity shocks are measured during the preannouncement period, announcement surprise is only available at the time of announcement. Since we have more than 30 prescheduled announcements, it is infeasible to include all of them in the estimation. Based on Table 5, we first include a set of 7 "important news" announcements in our benchmark model: consumer price index, change in nonfarm payrolls, retail sales, housing starts, ISM index, initial jobless claims, and producer price index. The rest of the announcements are added into the model one by one and are kept in the model only if their coefficients are significant. The 2 nd set of columns in Table 7 reports 
TABLE 6

Jumps, Information Shocks, and Liquidity Shocks

Table 6 reports the estimation results of the probit models for bond price jumps associated with a prescheduled news announcement, as specified in expressions (9), (10), and (11). The explanatory variables include return volatility (VOLA), shocks to spread (SPRDSHK), absolute order flow (OF), absolute order imbalance (OB), shocks to overall depth (DPTHSHK), shocks to overall hidden depth (HIDSHK), and announcement surprises of major macroeconomic news.

\begin{tabular}{|c|c|c|c|c|c|c|c|c|c|}
\hline \multirow[b]{2}{*}{$\begin{array}{l}\text { Explanatory } \\
\text { Variables }\end{array}$} & \multicolumn{3}{|c|}{$\begin{array}{l}\text { Liquidity } \\
\text { Shocks }\end{array}$} & \multicolumn{3}{|c|}{$\begin{array}{l}\text { Information } \\
\text { Shocks }\end{array}$} & \multicolumn{3}{|c|}{$\begin{array}{l}\text { Information vs. } \\
\text { Liquidity Shocks }\end{array}$} \\
\hline & Estimate & $\begin{array}{l}\text { Std. } \\
\text { Error }\end{array}$ & $p$-Value & Estimate & $\begin{array}{l}\text { Std. } \\
\text { Error }\end{array}$ & $p$-Value & Estimate & $\begin{array}{l}\text { Std. } \\
\text { Error }\end{array}$ & $p$-Value \\
\hline \multicolumn{10}{|l|}{ Panel A. 2-Year Note } \\
\hline $\begin{array}{l}\text { Intercept } \\
\text { VOLA } \\
\text { SPRDSHK } \\
\text { OF } \\
\text { OB } \\
\text { DPTHSHK } \\
\text { HIDSHK } \\
\text { Consumer price index } \\
\text { Initial jobless claims } \\
\text { ISM index } \\
\text { Change in nonfarm payrolls } \\
\text { Retail sales } \\
\text { Housing starts } \\
\text { Producer price index } \\
\text { Likelihood } \\
\text { Joint } \beta \text { LIQUIDITY }=0\end{array}$ & $\begin{array}{r}-1.764 \\
1.786 \\
0.234 \\
0.105 \\
-0.093 \\
-0.325 \\
0.037\end{array}$ & $\begin{array}{l}0.207 \\
0.498 \\
0.090 \\
0.091 \\
0.090 \\
0.140 \\
0.101\end{array}$ & $\begin{array}{c}<0.0001 \\
0.000 \\
0.009 \\
0.247 \\
0.305 \\
0.020 \\
0.716\end{array}$ & $\begin{array}{r}0.772 \\
0.047 \\
0.281 \\
1.091 \\
13.980 \\
-0.085 \\
28.329 \\
-105.956\end{array}$ & $\begin{array}{r}0.239 \\
0.177 \\
0.275 \\
0.370 \\
5.478 \\
0.504 \\
17.504\end{array}$ & $\begin{array}{l}0.001 \\
0.789 \\
0.307 \\
0.003 \\
0.011 \\
0.867 \\
0.106\end{array}$ & $\begin{array}{r}-2.302 \\
2.040 \\
0.182 \\
0.115 \\
0.000 \\
-0.287 \\
0.036 \\
0.791 \\
0.148 \\
0.279 \\
0.991 \\
18.333 \\
0.074 \\
29.256 \\
-95.617 \\
46.774\end{array}$ & $\begin{array}{r}0.300 \\
0.535 \\
0.114 \\
0.099 \\
0.096 \\
0.165 \\
0.109 \\
0.246 \\
0.195 \\
0.295 \\
0.382 \\
5.887 \\
0.517 \\
19.035\end{array}$ & $\begin{array}{c}<0.0001 \\
0.000 \\
0.112 \\
0.243 \\
0.999 \\
0.083 \\
0.739 \\
0.001 \\
0.448 \\
0.344 \\
0.009 \\
0.002 \\
0.886 \\
0.124 \\
\\
<0.0001\end{array}$ \\
\hline \multicolumn{10}{|l|}{ Panel B. 5-Year Note } \\
\hline $\begin{array}{l}\text { Intercept } \\
\text { VOLA } \\
\text { SPRDSHK } \\
\text { OF } \\
\text { OB } \\
\text { DPTHSHK } \\
\text { HIDSHK } \\
\text { Consumer price Index } \\
\text { Initial jobless claims } \\
\text { ISM index } \\
\text { Change in nonfarm payrolls } \\
\text { Retail sales } \\
\text { Housing starts } \\
\text { Producer price index } \\
\text { Likelihood } \\
\text { Joint } \beta \text { LIQUIDITY =0 }\end{array}$ & $\begin{array}{r}-1.548 \\
0.970 \\
0.259 \\
-0.172 \\
-0.091 \\
-0.253 \\
0.082\end{array}$ & $\begin{array}{l}0.242 \\
0.223 \\
0.097 \\
0.126 \\
0.121 \\
0.154 \\
0.103\end{array}$ & $\begin{array}{c}<0.0001 \\
<0.0001 \\
0.007 \\
0.174 \\
0.451 \\
0.100 \\
0.426\end{array}$ & $\begin{array}{r}0.340 \\
0.000 \\
0.548 \\
1.015 \\
6.734 \\
0.221 \\
27.567 \\
-114.879\end{array}$ & $\begin{array}{r}0.257 \\
0.166 \\
0.263 \\
0.278 \\
5.875 \\
0.499 \\
15.923\end{array}$ & $\begin{array}{l}0.186 \\
0.998 \\
0.038 \\
0.000 \\
0.252 \\
0.658 \\
0.083\end{array}$ & $\begin{array}{r}-1.838 \\
1.030 \\
0.146 \\
-0.246 \\
-0.045 \\
-0.320 \\
0.124 \\
0.370 \\
-0.011 \\
0.573 \\
0.971 \\
9.960 \\
0.474 \\
25.847 \\
-101.618 \\
47.078\end{array}$ & $\begin{array}{r}0.289 \\
0.235 \\
0.107 \\
0.137 \\
0.127 \\
0.165 \\
0.108 \\
0.271 \\
0.183 \\
0.280 \\
0.313 \\
6.209 \\
0.502 \\
16.124\end{array}$ & $\begin{array}{c}<0.0001 \\
<0.0001 \\
0.172 \\
0.071 \\
0.724 \\
0.053 \\
0.251 \\
0.171 \\
0.950 \\
0.041 \\
0.002 \\
0.109 \\
0.345 \\
0.109 \\
\\
<0.0001\end{array}$ \\
\hline \multicolumn{10}{|l|}{ Panel C. 10-Year Note } \\
\hline $\begin{array}{l}\text { Intercept } \\
\text { VOLA } \\
\text { SPRDSHK } \\
\text { OF } \\
\text { OB } \\
\text { DPTHSHK } \\
\text { HIDSHK } \\
\text { Consumer price index } \\
\text { Initial jobless claims } \\
\text { ISM index } \\
\text { Change in nonfarm payrolls } \\
\text { Retail sales } \\
\text { Housing starts } \\
\text { Producer price index } \\
\text { Likelihood } \\
\text { Joint } \beta_{\text {LIQUIDITY }=0}\end{array}$ & $\begin{array}{r}-2.064 \\
0.701 \\
0.314 \\
0.036 \\
-0.195 \\
-0.472 \\
0.002\end{array}$ & $\begin{array}{l}0.247 \\
0.119 \\
0.112 \\
0.123 \\
0.120 \\
0.164 \\
0.097\end{array}$ & $\begin{array}{c}<0.0001 \\
<0.0001 \\
0.005 \\
0.773 \\
0.102 \\
0.004 \\
0.984\end{array}$ & $\begin{array}{r}0.710 \\
-0.039 \\
0.771 \\
1.379 \\
16.493 \\
-0.438 \\
27.721 \\
-96.614\end{array}$ & $\begin{array}{r}0.251 \\
0.189 \\
0.279 \\
0.315 \\
6.035 \\
0.817 \\
17.849\end{array}$ & $\begin{array}{c}0.005 \\
0.835 \\
0.006 \\
<0.0001 \\
0.006 \\
0.592 \\
0.120\end{array}$ & $\begin{array}{r}-2.466 \\
0.672 \\
0.281 \\
0.030 \\
-0.228 \\
-0.548 \\
0.031 \\
0.269 \\
0.062 \\
0.709 \\
1.131 \\
17.730 \\
-0.719 \\
6.044 \\
-79.155 \\
76.766\end{array}$ & $\begin{array}{r}0.343 \\
0.136 \\
0.134 \\
0.144 \\
0.154 \\
0.209 \\
0.115 \\
0.310 \\
0.201 \\
0.300 \\
0.347 \\
6.247 \\
1.121 \\
20.910\end{array}$ & $\begin{array}{c}<0.0001 \\
<0.0001 \\
0.036 \\
0.836 \\
0.137 \\
0.009 \\
0.788 \\
0.385 \\
0.758 \\
0.018 \\
0.001 \\
0.005 \\
0.521 \\
0.773\end{array}$ \\
\hline
\end{tabular}

the estimation results of the previous model. For brevity, only the coefficient estimates of the previous 7 announcements are reported. The results indicate that change in nonfarm payrolls, ISM index, consumer price index, retail sales, and producer price index have the most significant explanatory power for jumps. 


\section{TABLE 7}

Post-Jump Price Discovery: Order Flow

Table 7 reports the coefficient estimates, standard errors, and p-values for the post-jump price discovery process specified in equation (12). The 1st set of columns contrasts the price discovery process after jumps versus days without jumps. For jump days, the order flows (OF) are observed every 5 minutes over the 60-minute horizon after jumps. For nonjump days, the order flows (OF) are observed every 5 minutes from 8:30 to 15:00 ET. The 2nd, 3rd, and 4th sets of columns restrict our analysis to days with prescheduled news announcements and contrasts the price discovery process after announcements with jumps versus those without. The model is estimated over 15-, 30-, and 60-minute horizons after jumps

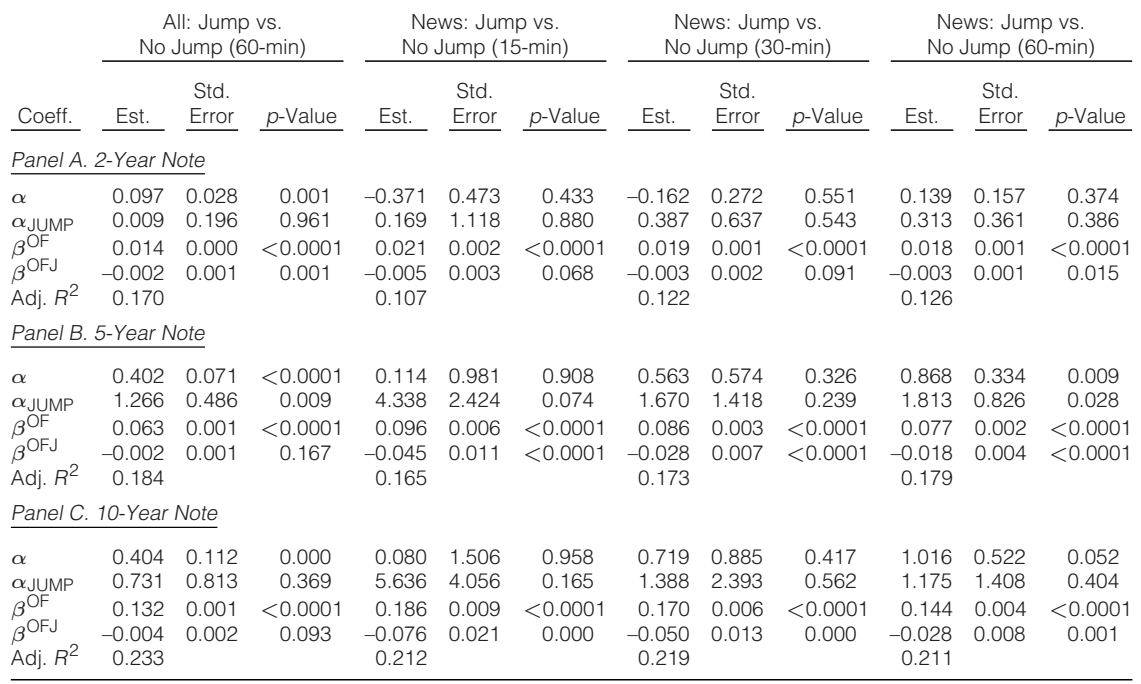

Finally, we estimate the following model with both announcement surprises and liquidity variables as explanatory variables:

$$
\begin{aligned}
& P\left(\mathrm{JUMP}_{t} \mid \text { ANNOUNCEMENT }\right)=f\left(\alpha+\beta_{\text {DPTHSHK } \text { DPTHSHK }_{t-1}}\right.
\end{aligned}
$$

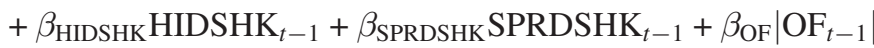

$$
\begin{aligned}
& \left.+\beta_{\mathrm{OB}}\left|\mathrm{OB}_{t-1}\right|+\beta_{\mathrm{VOLA}} \operatorname{VOLA}_{t-1}+\sum_{j=1}^{J} \gamma_{j}\left|\mathrm{SUR}_{j, t}\right|\right) \text {. }
\end{aligned}
$$

The purpose here is to test whether the predictive power of liquidity shocks is subsumed by information contained in announcement surprises. Estimation results are reported in the 3rd set of columns in Table 7. Interestingly, adding announcement surprise does not reduce the significance of market volatility and shocks to overall depth. The null hypothesis that the coefficients of all liquidity variables are jointly 0 remains strongly rejected for all maturities. In other words, the predictive power of these variables about upcoming jumps is not subsumed by surprises in macroeconomic news announcements. The results suggest that liquidity shocks contribute to bond price jumps beyond the effect of information shocks.

\section{B. Post-Jump Price Discovery}

In this subsection, we examine the price discovery process after jumps in bond prices. A number of studies have examined the price impact of order flows on both announcement and nonannouncement days (see, e.g., Green (2004), Brandt and Kavajecz (2004), Pasquariello and Vega (2007), and Menkveld et al. 
(2010)). Green (2004) and Menkveld et al. find that order flow is more informative after announcements. Brandt and Kavajecz find that order flow imbalances account for up to $26 \%$ of the day-to-day variation in yields on days without major macroeconomic announcements. The effect of order flow on yields is permanent and strongest when liquidity is low. They point out that order flow affects price discovery process in the Treasury market because some dealers may be more sophisticated in interpreting economic news. We extend the literature and address the following questions: What is the impact of jumps on the price discovery process in the bond market? In particular, do jumps tend to increase or reduce the informativeness of subsequent order flow in the bond market?

We first examine the post-jump price discovery process for all jump days, including both jumps at announcements and jumps outside announcement times, using nonjump days as a control sample. On jump days, order flows are observed every 5 minutes over the 60-minute interval after the jump. To avoid the effect of multiple jumps, we only include days with a single jump in our analysis. ${ }^{6}$ For nonjump days, order flows are observed every 5 minutes during the most active trading period from 8:30 ET to 15:00 ET. Specifically, let $j=0$ denote the 5-minute interval where a jump occurs; the post-jump period starts at the 5-minute interval $j=1$ (i.e., the interval right after the jump). We estimate the following model:

$$
p_{j+1}-p_{j}=\alpha+\alpha_{\mathrm{JUMP}} d_{\mathrm{JUMP}}+\beta^{\mathrm{OF}} \mathrm{OF}_{j+1}+\beta^{\mathrm{OFJ}} \mathrm{OF}_{j+1} d_{\mathrm{JUMP}}+\varepsilon_{j+1},
$$

where $p_{j}$ denotes the logarithmic mid-quote at the end of interval $j$, and $\mathrm{OF}_{j}$ is the order flow imbalance calculated from transactions during interval $j$. The dummy variable $d_{\text {JUMP }}$ takes a value of 1 for jump days, and 0 for nonjump days. Thus, the coefficient $\beta^{\mathrm{OF}}$ captures the price impact of order flow during nonjump days, whereas $\beta^{\mathrm{OFJ}}$ captures the additional price impact of post-jump order flow.

The results of 2-, 5-, and 10-year notes are reported in Table 7. Results for the 3-year note and the 30-year bond are similar and are not reported for brevity. Results in the first column of Table 7 show that consistent with the previous literature, $\beta^{\mathrm{OF}}$ is significantly positive, indicating that order flow is positively related to price. The coefficient $\beta^{\mathrm{OFJ}}$ is generally negative, suggesting that post-jump order flow has a lesser effect on bond prices. However, the coefficient estimate is only significant at the $10 \%$ level for the 2- and 10-year notes. Note that the above results are based on all sample days by simply separating the days with jumps from those without. This may potentially reduce the power of our analysis.

To sharpen our analysis, we next restrict our analysis only to jumps on announcement days, using announcement days without jumps as a control sample. To keep the analysis clean, announcement days with multiple jumps or jumps outside announcement times are excluded. To examine the post-jump effect over different time horizons, we estimate the model using order flows observed during 15-, 30-, and 60-minute time periods after jumps. The results are reported in the 2nd-4th sets of columns in Table 7. Similar to the results in the 1st set of columns, $\beta^{\mathrm{OF}}$ is significantly positive for all 5 maturities. Since we now focus on news announcement days, $\beta^{\mathrm{OF}}$ tends to have a larger magnitude than those in the 1 st set of

\footnotetext{
${ }^{6}$ The results are robust when multiple-jump days are included in the analysis.
} 
columns, indicating that order flow has a stronger price effect on announcement days. Also similar to the results in the 1 st set of columns, the coefficient $\beta^{\mathrm{OFJ}}$ is negative for all maturities. Note that the coefficients $\beta^{\mathrm{OFJ}}$ are now statistically significant at $10 \%$ level for all maturities. This suggests that the post-jump order flow imbalance has significantly less effect on bond prices compared to announcement days with no jumps. The results are largely consistent over the 15-, 30-, and 60-minute post-jump horizons, except that $\beta^{\mathrm{OFJ}}$ decreases in magnitude as time horizon increases.

A direct interpretation of the finding is that when a jump occurs, information contained in the news announcement is incorporated quickly into bond prices. Thus, subsequent order flows tend to have less impact on bond prices. Of course, it is also possible that price discovery could slow down after jumps if there is a lack of trading. However, as shown in Figure 2, we observe a surge in trading volume after jumps. This evidence provides further support that post-jump order flow has a less informational role. A possible explanation for the reduced order flow effect is the low dispersion of investor belief immediately following jumps. Using a parsimonious model of speculative trading, Pasquariello and Vega (2007) show that the information content of order flow is positively related to the dispersion of investor belief. The patterns documented in our study suggest that when information uncertainty at announcement is resolved in the form of jumps, the dispersion of investor belief is low and, thus, order flow becomes less informative. This conjecture is also supported by postannouncement market activities shown in Figure 2. While the postannouncement trading volume on days with jumps is substantially higher than on days with no jumps, both return volatility and the bid-ask spread during the postannouncement period are comparable between days with jumps and those without, indicating convergence of investor belief following jumps.

\section{Conclusion}

Using the intraday data from the BrokerTec electronic trading platform, we identify jumps in U.S. T-bond prices and investigate what causes such unexpected large price changes. In particular, we examine the relative importance of macroeconomic news announcements versus liquidity shocks in explaining the observed jumps. In addition, we examine the informativeness of order flow immediately after bond price jumps.

We find that a majority of jumps occurs around macroeconomic news announcements. Nevertheless, announcement surprises have limited explanatory power for jumps. Further analysis shows that liquidity shocks during the preannouncement period also play an important role for bond price jumps. We document some significantly different patterns between announcement days with jumps and those without. We show that prior to announcements with jumps, there is a more dramatic widening of the bid-ask spread and a more significant drop in market depth. Moreover, the predictive power of liquidity shocks for upcoming jumps is not subsumed by unexpected information shocks.

Finally, examining the post-jump price discovery process, we find that order flow is in general less informative immediately after jumps compared to the case 
where there is no jump at announcement. This finding, coupled with a post-jump surge of trading volume, suggests that jumps serve as a dramatic form of price discovery, and post-jump order flow has less impact on bond prices.

\section{Appendix A. Identification of Jump Returns}

When the null hypothesis of no jump is rejected, the following procedure is used to identify jump returns.

Step 1. Let $\left\{r_{1}, r_{2}, \ldots, r_{N}\right\}$ be log return observations during the testing period. If the jump test statistic $\mathrm{JS}_{0}$ is significant, we record $\mathrm{JS}_{0}$ and continue to Step 2.

Step 2. We replace each of the return observations $r_{i}(i=1, \ldots, N)$ by the median return of the sample (denoted by $r_{\text {med }}$ ), and perform jump tests on $\left\{r_{1}, \ldots, r_{i-1}, r_{\text {med }}, r_{i+1}, \ldots, r_{N}\right\}$. The test statistics $\mathrm{JS}^{(i)}, i=1,2, \ldots, N$ are recorded.

Step 3. We compute the differences of the jump test statistic in Step 1 with those in Step 2 (i.e., $\left.\mathrm{JS}_{0}-\mathrm{JS}^{(i)}, i=1,2, \ldots, N\right)$. Return $j$ is identified as a jump return if $\mathrm{JS}_{0}-\mathrm{JS}^{(j)}$ has the highest value. This criterion is in the spirit of the likelihood ratio test, since $r_{j}$ is the return that contributes most to the jump test to reject the null hypothesis.

Step 4. Replace the identified jump, $r_{j}$, by the median of returns, and we have a new sample of return observations $\left\{r_{1}, \ldots, r_{j-1}, r_{\text {med }}, r_{j+1}, \ldots, r_{N}\right\}$. Then start over again from Step 1.

The previous procedure continues until all jumps are identified. Andersen et al. (2010) propose a similar procedure for identifying intraday jump returns. The main difference is that instead of using the median of the sample to replace each single return in Step 2 of the sequential procedure, they use the mean of the remaining $N-1$ returns. To take into account the market microstructure effect, we modify the SWV jump test by allowing measurement error in the observed asset prices, that is, $\hat{P}_{t}=P_{t}+\epsilon_{t}$, where $P_{t}$ is the intrinsic price of the asset, and $\epsilon_{t}$ is the noise. The standard error of $\epsilon_{t}$ is estimated based on the 1 st-order autocorrelation of the return process. Details can be found in Jiang and Oomen (2008). In addition, to ensure that identified jump returns are not the result of discrete tick size or bid-ask bounce, we also impose a condition that the absolute jump return has to be more than twice the tick size. We find that this restriction virtually has no effect on our identified jump returns.

\section{Appendix B. Monte Carlo Simulations of the Jump Tests}

In our simulation, the following stochastic volatility jump-diffusion model is used as the data generating process (DGP):

$$
\begin{aligned}
d S_{t} / S_{t} & =\mu d t+\sqrt{V_{t}} d W_{t}^{s}+J_{t} d q_{t}, \\
d V_{t} & =\beta\left(\alpha-V_{t}\right) d t+\sigma \sqrt{V_{t}} d W_{t}^{v},
\end{aligned}
$$

where $d W_{t}^{s} d W_{t}^{v}=\rho d t$.

For the benchmark case, the model parameter values are set as $\mu=0, \rho=0, \alpha=$ mean of daily variance of the 2 -year note, the value of $\beta$ is determined by $e^{-\beta}=1$ st-order autocorrelation of daily variance, and $\sigma$ is set from $\left(\alpha \sigma^{2}\right) /(2 \beta)=$ variance of daily return variance. That is: $\mu=0, \rho=0, \alpha=0.005, \beta=0.8, \sigma=0.10$. We also consider 6 alternative sets of parameter values as follows:

Alternative I parameter values: $\mu=0, \rho=0, \alpha=0.005, \beta=0.2, \sigma=0.10$.

Alternative II parameter values: $\mu=0, \rho=0, \alpha=0.005, \beta=1.6, \sigma=0.10$. 
Alternative III parameter values: $\mu=0, \rho=0, \alpha=0.005, \beta=0.8, \sigma=0.05$. Alternative IV parameter values: $\mu=0, \rho=0, \alpha=0.005, \beta=0.8, \sigma=0.20$. Alternative $\mathrm{V}$ parameter values: $\mu=0, \rho=0.50, \alpha=0.005, \beta=0.8, \sigma=0.10$. Alternative VI parameter values: $\mu=0, \rho=-0.50, \alpha=0.005, \beta=0.8, \sigma=0.10$.

Each "day," we simulate a sample path of the return process specified in expression (B-1) using the Euler scheme with a 1-minute discretization interval over a total of 9.5 hours. Then we sample returns at a 5-minute interval. To examine size, we set the jump return to 0 (i.e., $J=0$ ). To examine power, jumps $(J)$ are added to the 30th observation of 5 -minute returns, and we set $J=4 \times \sqrt{\alpha}, 7 \times \sqrt{\alpha}, 10 \times \sqrt{\alpha}$, respectively, in our simulation. Jump tests are performed on the 5-minute return observations at the $1 \%$ critical level. The procedure is repeated 10,000 times. The results in Table B1 indicate that at the $1 \%$ critical level, both the BPV and SWV tests tend to overreject the null hypothesis of no jumps, with the size clearly above $1 \%$. The results are consistent with Huang and Tauchen (2005). However, the size of the joint BPV and SWV tests is much improved, generally below but much closer to $1 \%$. Thus, the joint approach substantially mitigates the size problem. As expected, the combined test has lower power. However, when the jump size is large (more than $4 \times$ the return standard deviation), the joint test procedure does not sacrifice much of the power and works well in picking up large jumps.

TABLE B1

Size and Power of Jump Tests (\%)

\begin{tabular}{|c|c|c|c|c|c|c|c|c|}
\hline \multirow[b]{2}{*}{ Jump Size } & \multirow[b]{2}{*}{ Jump Test } & \multicolumn{7}{|c|}{ Scenarios } \\
\hline & & Benchmark & $\mathrm{A} 1$ & A2 & A3 & A4 & A5 & A6 \\
\hline $0 \times \sqrt{\alpha}$ & $\begin{array}{l}\text { BPV } \\
\text { SWV } \\
\text { Joint }\end{array}$ & $\begin{array}{l}3.40 \\
4.65 \\
0.75\end{array}$ & $\begin{array}{l}3.01 \\
4.50 \\
0.72\end{array}$ & $\begin{array}{l}2.80 \\
4.34 \\
0.48\end{array}$ & $\begin{array}{l}2.75 \\
2.99 \\
0.32\end{array}$ & $\begin{array}{l}4.13 \\
6.34 \\
1.29\end{array}$ & $\begin{array}{l}3.30 \\
4.44 \\
0.62\end{array}$ & $\begin{array}{l}3.18 \\
4.13 \\
0.57\end{array}$ \\
\hline $4 \times \sqrt{\alpha}$ & $\begin{array}{l}\text { BPV } \\
\text { SWV } \\
\text { Joint }\end{array}$ & $\begin{array}{l}54.25 \\
73.65 \\
51.12\end{array}$ & $\begin{array}{l}55.27 \\
72.21 \\
52.49\end{array}$ & $\begin{array}{l}51.62 \\
75.50 \\
48.58\end{array}$ & $\begin{array}{l}49.49 \\
82.81 \\
46.87\end{array}$ & $\begin{array}{l}53.17 \\
63.49 \\
48.97\end{array}$ & $\begin{array}{l}53.90 \\
75.46 \\
51.38\end{array}$ & $\begin{array}{l}53.90 \\
72.90 \\
50.49\end{array}$ \\
\hline $7 \times \sqrt{\alpha}$ & $\begin{array}{l}\text { BPV } \\
\text { SWV } \\
\text { Joint }\end{array}$ & $\begin{array}{l}93.72 \\
99.13 \\
93.56\end{array}$ & $\begin{array}{l}90.97 \\
98.40 \\
90.65\end{array}$ & $\begin{array}{l}94.42 \\
99.72 \\
94.40\end{array}$ & $\begin{array}{l}97.23 \\
99.96 \\
97.22\end{array}$ & $\begin{array}{l}85.45 \\
93.21 \\
84.36\end{array}$ & $\begin{array}{l}92.45 \\
99.49 \\
92.39\end{array}$ & $\begin{array}{l}92.99 \\
98.65 \\
92.71\end{array}$ \\
\hline $10 \times \sqrt{\alpha}$ & $\begin{array}{l}\text { BPV } \\
\text { SWV } \\
\text { Joint }\end{array}$ & $\begin{array}{r}99.42 \\
100.00 \\
99.42\end{array}$ & $\begin{array}{l}98.98 \\
99.97 \\
98.96\end{array}$ & $\begin{array}{r}99.70 \\
100.00 \\
99.70\end{array}$ & $\begin{array}{r}99.92 \\
100.00 \\
99.92\end{array}$ & $\begin{array}{l}95.97 \\
99.14 \\
95.81\end{array}$ & $\begin{array}{r}99.41 \\
100.00 \\
99.41\end{array}$ & $\begin{array}{l}99.43 \\
99.98 \\
99.42\end{array}$ \\
\hline
\end{tabular}

\section{References}

Aitt-Sahalia, Y. "Telling from Discrete Data Whether the Underlying Continuous-Time Model Is a Diffusion.” Journal of Finance, 57 (2002), 2075-2112.

Aït-Sahalia, Y., and J. Jacod. "Testing for Jumps in a Discretely Observed Process." Annals of Statistics, 37 (2009), 184-222.

Andersen, T. G.; T. Bollerslev; F. X. Diebold; and P. Labys. "Modeling and Forecasting Realized Volatility." Econometrica, 71 (2003), 579-625.

Andersen, T. G.; T. Bollerslev; F. X. Diebold; and C. Vega. "Real-Time Price Discovery in Stock, Bond and Foreign Exchange Markets.” Journal of International Economics, 73 (2007), 251-277.

Andersen, T. G.; T. Bollerslev; P. Frederiksen; and M. Nielsen. "Continuous-Time Models, Realized Volatilities, and Testable Distributional Implications for Daily Stock Returns.” Journal of Applied Econometrics, 25 (2010), 233-261.

Balduzzi, P.; E. J. Elton; and T. C. Green. "Economic News and Bond Prices: Evidence from the U.S. Treasury Market." Journal of Financial and Quantitative Analysis, 36 (2001), 523-543.

Barclay, M. J.; T. Hendershott; and K. Kotz. "Automation versus Intermediation: Evidence from Treasuries Going Off the Run.” Journal of Finance, 61 (2006), 2395-2414. 
Barndorff-Nielsen, O. E., and N. Shephard. "Power and Bipower Variation with Stochastic Volatility and Jumps." Journal of Financial Econometrics, 2 (2004), 1-48 (with discussion).

Barndorff-Nielsen, O. E., and N. Shephard. "Econometrics of Testing for Jumps in Financial Economics Using Bipower Variation." Journal of Financial Econometrics, 4 (2006), 1-30.

Beber, A., and M. W. Brandt. "Resolving Macroeconomic Uncertainty in Stock and Bond Markets." Review of Finance, 13 (2009), 1-45.

Bollerslev, T.; J. Cai; and F. M. Song. "Intraday Periodicity, Long Memory Volatility, and Macroeconomic Announcement Effects in the U.S. Treasury Market." Journal of Empirical Finance, 7 (2000), 37-55.

Brandt, M. W., and K. A. Kavajecz. "Price Discovery in the U.S. Treasury Market: The Impact of Orderflow and Liquidity on the Yield Curve." Journal of Finance, 59 (2004), 2623-2654.

Brandt, M. W.; K. A. Kavajecz; and S. E. Underwood. "Price Discovery in the Treasury Futures Market." Journal of Futures Market, 27 (2007), 1021-1051.

Cao, C.; O. Hansch; and X. Wang. "The Informational Content of an Open Limit-Order Book.” Journal of Futures Markets, 29 (2009), 16-41.

Carr, P., and L. Wu. "What Type of Process Underlies Options? A Simple Robust Test." Journal of Finance, 58 (2003), 2581-2610.

Dungey, M.; M. MacKenzie; and L. V. Smith. "Empirical Evidence on Jumps in the Term Structure of the U.S. Treasury Market.” Journal of Empirical Finance, 16 (2009), 430-445.

Evans, M. D. D. "FX Trading and Exchange Rate Dynamics." Journal of Finance, 57 (2002), 24052447.

Evans, M. D. D., and R. K. Lyons. "Order Flow and Exchange Rate Dynamics.” Journal of Political Economy, 110 (2002), 170-180.

Fleming, M. J., and B. Mizrach. "The Microstructure of a U.S. Treasury ECN: The BrokerTec Platform." Working Paper, Federal Reserve Bank of New York (2009).

Fleming, M., and M. Piazzesi. "Monetary Policy Tick-by-Tick," NBER chapters. In Market Microstructure Meeting, National Bureau of Economic Research, Inc. (2006).

Fleming, M. J., and E. M. Remolona. "What Moves the Bond Market?" Federal Reserve Bank of New York Economic Policy Review, 3 (1997), 31-50.

Fleming, M. J., and E. M. Remolona. "Price Formation and Liquidity in the U.S. Treasury Market: The Response to Public Information.” Journal of Finance, 54 (1999), 1901-1915.

Green, T. C. "Economic News and the Impact of Trading on Bond Prices." Journal of Finance, 59 (2004), 1201-1233.

Harris, L. E., and V. Panchapagesan. "The Information Content of the Limit Order Book: Evidence from the NYSE Specialist Trading Decisions.” Journal of Financial Markets, 8 (2005), 25-67.

Huang, X., and G. Tauchen. "The Relative Contribution of Jumps to Total Price Variance." Journal of Financial Econometrics, 3 (2005), 456-499.

Jacod, J., and A. N. Shiryaev. Limit Theorems for Stochastic Processes. Berlin, Germany: Springer (1987).

Jiang, G. J., and R. C. A. Oomen. "Testing for Jumps When Asset Prices Are Observed with Noise: A 'Swap Variance’ Approach.” Journal of Econometrics, 144 (2008), 352-370.

Lahaye, J.; S. Laurent; and C. Neely. "Jumps, Cojumps, and Macro Announcements." Journal of Applied Econometrics, forthcoming (2011).

Lee, S. S., and P. A. Mykland. "Jumps in Financial Markets: A New Nonparametric Test and Jump Dynamics." Review of Financial Studies, 21 (2008), 2535-2563.

Menkveld, A. J.; A. Sarkar; and M. van der Wel. "Customer Order Flow, Intermediaries, and the Discovery of the Equilibrium Riskfree Rate.” Working Paper, Federal Reserve Bank of New York (2010).

Mizrach, B., and C. Neely. "Information Shares in the U.S. Treasury Market." Journal of Banking and Finance, 32 (2008), 1221-1233.

Mizrach, B., and C. Neely. "The Microstructure of the U.S. Treasury." In Encyclopedia of Complexity and Systems Science, R. A. Meyers, ed. New York, NY: Springer-Verlag (2009).

Neuberger, A. "The Log Contract: A New Instrument to Hedge Volatility." Journal of Portfolio Management, 20 (1994), 74-80.

Pasquariello, P., and C. Vega. "Informed and Strategic Order Flow in the Bond Markets." Review of Financial Studies, 20 (2007), 1975-2019. 